\title{
Fall from grace: The role of dominance and prestige in the punishment of high-status actors
}

\begin{tabular}{|c|c|}
\hline Journal: & Academy of Management Journal \\
\hline Manuscript ID & AMJ-2017-0729.R3 \\
\hline Manuscript Type: & Revision \\
\hline Keywords: & $\begin{array}{l}\text { Lab experiment < Quantitative Orientation < Research Methods, } \\
\text { Attitudes, cognitions, and affect (General) < Attitudes, Cognitions, and } \\
\text { Affect < Organizational Behavior < Topic Areas, Leadership }< \\
\text { Organizational Behavior }<\text { Topic Areas, Decision making (micro } \\
\text { perspectives) }<\text { Behavior }<\text { Organizational Behavior }<\text { Topic Areas, } \\
\text { Behavior (General) }<\text { Behavior }<\text { Organizational Behavior }<\text { Topic Areas, } \\
\text { Deviance/counterproductive behaviors }<\text { Behavior }<\text { Organizational } \\
\text { Behavior < Topic Areas }\end{array}$ \\
\hline Abstract: & $\begin{array}{l}\text { When actors transgress social norms, their social status colors the } \\
\text { severity with which they are punished. While some argue that high- } \\
\text { status transgressors attract severe punishment when accused of } \\
\text { ambiguous transgressions, others contend the opposite. In this paper, } \\
\text { we attempt to reconcile this theoretical inconsistency. We propose that } \\
\text { the capacity for social status to color third-party judgments of } \\
\text { transgressions may depend on the status type of high-status actors. } \\
\text { Drawing on the evolutionary theory of dominance and prestige as two } \\
\text { alternate forms of status within social hierarchies, we suggest that actors } \\
\text { associated with dominance-based status will be penalized more harshly } \\
\text { than actors whose status is based on prestige. Across multiple studies } \\
\text { employing archival field data, controlled lab experiments, and different } \\
\text { instantiations of dominance, prestige, and misconduct, we consistently } \\
\text { demonstrate that high-status dominant actors are punished more } \\
\text { harshly than their prestigious counterparts. Further, we find that } \\
\text { attributions of intentionality and lack of moral credentials explain the } \\
\text { harsher punishments meted out to dominant (versus prestigious) high- } \\
\text { status actors. In this way, we provide both a parsimonious reconciliation } \\
\text { of the inconsistency in the extant literature and a theoretical explanation } \\
\text { of how status type of high-status actors differentially impacts the } \\
\text { judgment, decisions, and behaviors of third parties. }\end{array}$ \\
\hline
\end{tabular}




\title{
Fall from Grace: The Role of Dominance and Prestige in The Punishment of High-Status Actors
}

\author{
Hemant Kakkar \\ London Business School \\ hkakkar@london.edu \\ Niro Sivanathan \\ London Business School \\ nsivanathan@london.edu \\ Matthias S. Gobel \\ University of California, Santa Barbara \\ gobel@sagecenter.ucsb.edu
}

\begin{abstract}
Acknowledgements
The authors are thankful for the exceptional editorial guidance of Katy DeCelles and helpful suggestions of the three anonymous reviewers who have helped improve the manuscript quality. The authors also wish to thank Selin Kesebir and Madan Pillutla for their helpful comments on an earlier draft of this paper. We are also grateful to the Leadership Institute grant and the RAMD grant at the London Business School who funded this project. Finally, we would like to acknowledge the exceptional support of Zareen, Sharmay, Oliver, and the Behavioral Lab team at the London Business School for their help with data collection and data coding.
\end{abstract}




\title{
FALL FROM GRACE: THE ROLE OF DOMINANCE AND PRESTIGE IN THE PUNISHMENT OF HIGH-STATUS ACTORS
}

\begin{abstract}
When actors transgress social norms, their social status colors the severity with which they are punished. While some argue that high-status transgressors attract severe punishment when accused of ambiguous transgressions, others contend the opposite. In this paper, we attempt to reconcile this theoretical inconsistency. We propose that the capacity for social status to color third-party judgments of transgressions may depend on the status type of high-status actors. Drawing on the evolutionary theory of dominance and prestige as two alternate forms of status within social hierarchies, we suggest that actors associated with dominance-based status will be penalized more harshly than actors whose status is based on prestige. Across multiple studies employing archival field data, controlled lab experiments, and different instantiations of dominance, prestige, and misconduct, we consistently demonstrate that high-status dominant actors are punished more harshly than their prestigious counterparts. Further, we find that attributions of intentionality and lack of moral credentials explain the harsher punishments meted out to dominant (versus prestigious) high-status actors. In this way, we provide both a parsimonious reconciliation of the inconsistency in the extant literature and a theoretical explanation of how status type of high-status actors differentially impacts the judgment, decisions, and behaviors of third parties.
\end{abstract}

Keywords: Status, dominance, prestige, punishment, transgression, moral credentials, deviance

Our social landscape is dotted with individuals severely reprimanded for norm and moral violations, while others are excused for similar misdeeds. For instance, consider the differential fates of Tim Geithner and Tom Daschle, two individuals bestowed with high status, operating at the apex of U.S. politics. Geithner played an important role during the 2008 financial crisis when he served as the President of the Federal Reserve Bank of New York. Similarly, Daschle was a well-known figure in the U.S. political circuit who served as the longstanding Senator from South Dakota and leader of both the majority and minority Senate. Given their credentials, both men were nominated for secretary positions in 2009: Geithner for the U.S. Department of the Treasury and Daschle for the U.S. Department of Health and Human Services (Hiebert-White, 2008; Sahadi, 2008). Around the same time, both were accused of tax fraud for not paying taxes on certain incomes and gifts (Staff, 2012). Both Geithner and Daschle described their behavior as a mistake and "unintentional" (Brown, 2009; Spak, 2009). However, the parallels between the 
two men ended there. Geithner successfully went on to become the $75^{\text {th }}$ United States Secretary of the Treasury (Calmes, 2009). In contrast, Daschle was forced to withdraw his nomination for the same position (Zeleny \& Stout, 2009). In short, both individuals were perched at the top of their respective domains, committed virtually identical infractions, and claimed those infractions to be unintentional—yet their outcomes were wildly different.

Similar inconsistencies abound in the corporate world. In 2008, Sam Israel III, hedge fund manager at Bayou Hedge Fund Group, was sentenced to 20 years in prison for defrauding investors of over $\$ 450$ million (Weidlich \& Glovin, 2008). But in 2011, three Olympus executives who covered up $\$ 1.5$ billion in investment losses_-recognized as one of the largest frauds in corporate history—successfully avoided serving any jail time at all (Tabuchi, 2013).

In these examples, the transgressors shared a similar level of status; they were ranked at the top of their fields and held great influence over others. Yet, some were punished harshly for their alleged ethical violations while others were excused. What underlying factors cause similar acts of transgression from equally high-status actors to be evaluated differently? Extant research across sociology, psychology, and management provides insight as to how a transgressor's status colors observers' judgments and the punishment exercised on these transgressors (Bowles \& Gelfand, 2009; Fragale, Rosen, Xu, \& Merideth, 2009; Giordano, 1983; Graffin, Bundy, Porac, Wade, \& Quinn, 2013; Karelaia \& Keck, 2013; Loeffler \& Lawson, 2002; Polman, Pettit, \& Wiesenfeld, 2013; Rosoff, 1989; Swigert \& Farrell, 1977). Although this extensive work successfully demonstrates the critical role of transgressor status in influencing observer punishment, it also presents contradictory findings, especially when the transgressor's status is high and the transgression is ambiguous. "Ambiguous transgressions" refer to norm violations that are not blatant infractions and leave open the possibility that the act could be perceived as an 
honest mistake or an unintentional act (Polman et al., 2013; van Prooijen, 2006). With respect to blatant transgressions, findings consistently demonstrate that high-status individuals are punished more harshly than low-status individuals for such behaviors (e.g., Karelaia \& Keck, 2013; Polman et al., 2013; Rosoff, 1989). However, when it comes to ambiguous transgressions, some studies find that high status results in greater punishment, others find that high status buffers the impact of others' condemnation for similar misbehaviors (see, e.g., Fragale et al., 2009; Polman et al., 2013). In this way, existing research has failed to elucidate why some high-status actors are reprimanded for their ambiguous misdeeds while others are excused. Our work aims to address this lack of crucial theoretical understanding within the status literature.

We build on the evolutionary social psychology theory of status, which suggests that high status can be based on either dominance or prestige (Henrich \& Gil-White, 2001; Maner \& Case, 2016). Those whose status is associated with dominance are generally assertive, decisive, and controlling in their behavior towards others. The self-assured and confident demeanor of these dominant individuals is perceived as a signal of greater competence, which results in them being conferred with higher status or leadership positions (Anderson \& Kilduff, 2009; Foti \& Hauenstein, 2007; Lord, de Vader, \& Alliger, 1986). On the other hand, those individuals whose status is associated with prestige are respected and admired because of their willingness to share their knowledge and skills with others (Henrich \& Gil-White, 2001); in exchange for such generosity, they are bestowed with higher status (Flynn, 2003; Flynn, Reagans, Amanatullah, \& Ames, 2006; Willer, 2009). As a result, dominance and prestige are recognized as alternative forms of status (Cheng, Tracy, Foulsham, Kingstone, \& Henrich, 2013). In this research, building on third-party attribution theories (Malle \& Knobe, 1997; Skarlicki \& Kulik, 2004), we 
argue that the particular status type associated with a high-status actor (i.e., either dominance or prestige) determines whether that actor will be harshly punished for ambiguous transgressions.

Our research offers several important contributions. First, we provide a theoretical rationale for the inconsistent findings of extant organizational research on high-status actor's transgression, and punishment. Second, in resolving this theoretical tension, we offer a more nuanced and parsimonious account highlighting the role of two different status types through which status yields its benefits and associated costs. Third, our findings are also relevant to the retributive justice literature, highlighting how transgressors' characteristics (e.g., status type) influence observers' desire to punish them. Fourth, our research contributes to the existing literature on organizational reputation following misconduct by any key member(s) of the organization (Elsbach \& Sutton, 1992).

\section{STATUS, ATTRIBUTIONS OF WRONGDOING, AND PUNISHMENT}

Status is broadly defined as an individual's social rank within a formal or informal hierarchy, or a person's relative standing along a valued social dimension (Báles, Strodtbeck, Mills, \& Roseborough, 1951; Magee \& Galinsky, 2008; Pettit, Sivanathan, Gladstone, \& Marr, 2013). A high-status individual, by virtue of his or her ability or knowledge, helps the group to attain its goals (Berger, Cohen, \& Zelditch, 1972). Consequently, high-status individuals enjoy greater deference from, as well as influence over, those who are positioned lower in the social hierarchy (Anderson \& Brown, 2010). In other words, status is a property that rests in the eyes of others and is conferred to individuals who are deemed to have a higher rank or social standing in a pecking order based on a mutually valued set of social attributes (Magee \& Galinsky 2008).

Higher social status or rank grants its holder a host of tangible benefits in both professional and personal domains. For instance, high-status actors are sought by groups for advice (Berger, Rosenholtz, \& Zelditch, 1980), are paid higher (Wade, Porac, Pollock, \& 
Graffin, 2006), receive unsolicited help (Van der Vegt, Bunderson, \& Oosterhof, 2006), and are credited disproportionately in joint tasks (Merton, 1968) and for expressing ideas in the workplace (Howell, Harrison, Burris, \& Detert, 2015). In innumerable ways, our social ecosystem consistently rewards those with high status.

In addition to these benefits, it has been suggested that high status protects actors when transgressing social norms. For example, Hollander (1958) contends that high status affords its owner idiosyncratic credits, and that the "positively disposed impressions" (p. 120) in the eyes of others allow those with high status to evade sanctions when they deviate from expected norms. However, empirical tests of this proposition have been inconclusive. Fragale et al. (2009) demonstrate that despite the transgression being ambiguous i.e., when one could also interpret the infraction as an honest mistake, high-status actors are punished harshly and assigned greater intentionality for the misdeed. These attributions of intentionality explain the harsher punishments advocated for high-status actors. Giordano (1983) argues that even small acts of deviance by high-status actors are met with greater sanctioning as they are held more accountable for their actions than those with low status. Indeed, winners of Financial World's annual "CEO of the Year" competition suffered greater salary loss following unsatisfactory firm performance than CEOs who were not the winners (Wade et al., 2006). Another study found that, for the same alleged offense, high-status British parliamentarians were subjected to greater accountability and sanctioning than low-status legislators (Graffin et al., 2013). Thus, instead of being an asset, high status appears to be a liability for those who transgress.

In contrast, Polman et al. (2013) find that high-status actors are punished less than their low-status counterparts when the transgression is ambiguous - a set of results contrary to those above, but in line with Hollander's assertion (1958). Likewise, individuals with greater 
occupational status are punished less for an ambiguous moderate level of offense, and expected to transgress less in the future compared to individuals with low occupational status (Loeffler \& Lawson, 2002; Rosoff, 1989). An archival study of court sentencing found that for similar crimes, high social-status individuals received less harsh punishment and were awarded greater numbers of bails, guilty pleas, and lenient convictions than those with low status (Swigert \& Farrell, 1977). Further, a meta-analysis of jury decision-making found that individuals associated with higher socioeconomic status were less likely to be associated with guilty judgments compared to those associated with low socioeconomic status (Devine \& Caughlin, 2014). In short, there is ample empirical evidence that high-status actors are punished less than their lowstatus counterparts, especially when the transgression is ambiguous.

Taken together, the literature to date remains inconclusive and contradictory to the punishment handed out to high-status actors following ambiguous transgressions. At times, high status seems to benefit the transgressor, affording others a rose-tinted evaluation of their misdeeds, while at other times, it hurts the transgressor, inviting a more critical evaluation. Hence, in this research, we explore a theoretically grounded explanation for these inconsistent findings. Specifically, we examine both when and why high-status actors are punished less versus more following ambiguous norm violations. We suggest observers' interpretation of high-status actors' ambiguous misdeeds depends primarily on whether the actor's status is one based on dominance or prestige.

\section{Theoretical Boundary Conditions}

It is important to note the possibility of other factors that could theoretically moderate our prediction. For instance, transgressions that benefit ingroup members at a cost to outgroup members can attenuate punishment directed towards high-status dominant individuals. In these instances, high-status individuals appear more socially engaged and helpful towards the group 
(Halevy, Chou, Cohen, \& Livingston, 2012; Van Kleef, Homan, Finkenauer, Blaker, \& Heerdink, 2012). Additionally, the identity of the third-party observer vis-à-vis the high-status actor could also influence judgments about the high-status actor's punishment. Existing work highlights that social identity could lead to both the ingroup leniency effect, where the ingroup member receives lenient punishment (Sommers \& Ellsworth, 2000), or the "black sheep" effect, where the ingroup member is harshly punished (Marques \& Paez, 1994). Although these boundary conditions are beyond the scope of this investigation, future investigation could explore the relevance of these contingency factors.

\section{THEORY}

\section{Dominance and Prestige: Two Alternate Forms of Status}

Drawing on the evolutionary theory of social structures that enhance and maximize group members' fitness, Henrich and Gil-White (2001) contend that rank allocation in social hierarchies can either be based on dominance or prestige (Cheng et al., 2013; Cheng, Tracy, \& Henrich, 2010; Halevy et al., 2012; Maner \& Case, 2016). Group members who attain and maintain high rank by behaving in ways that are assertive, controlling, and intimidating are characterized as dominant (Maner \& Case, 2016). Such individuals are quick to voice their opinions, take control of group decisions, and influence others' outcomes in an attempt to gain superiority over others (Cheng et al., 2013). They are also adept at forming and breaking alliances with other members as long as it serves the purpose of preserving their higher rank (Maner \& Case, 2016). Given their confident and assertive behavior, dominant individuals are perceived as competent and granted higher status (Anderson \& Kilduff, 2009).Their dominant attributes are especially valued when faced with inter-group competition, threat, or uncertainty; circumstances that often elevate dominant individuals into leadership positions (Halevy et al., 2012; Kakkar \& Sivanathan, 2017). In such situations, leaders associated with dominance are 
able to enforce coordinated and collective action among group members, thereby increasing group efficiency and performance (Laustsen \& Petersen, 2015; Van Vugt, 2006). Thus, invariably, a high-status dominant actor is a highly agentic member of the group, who is assertive, controlling, and decisive (Maner \& Case, 2016). Often, dominance overlaps with power, in that one has asymmetric control over resources and is therefore able to influence others' actions (Emerson, 1962). Crucially, however, dominance is present with or without formal rank authority and can be observed even in groups void of institutional roles; in this way, it differs conceptually from formal power relationships (see Cheng et al., 2013 for details).

As noted, high status can also be based on prestige, conferred to those who are respected and admired for their set of skills, knowledge, expertise, and their willingness to share these with others (Henrich \& Gil-White, 2001; Maner \& Case, 2016). Transmission of such valuable social information enhances the fitness of other members, who can reliably depend upon the superior knowledge and skills of these individuals and maximize their chances of success. Hence, these highly skilled and helpful individuals are bestowed with status in the form of admiration, respect, or recognition for their skills and cooperation (Henrich \& Gil-White, 2001; Maner \& Case, 2016). As a result, "prestige is determined by the perceiver and, as such, necessarily lies in the eyes of the beholder" (Maner \& Case, 2016: 138). Prestige-based status is similar to the reputation construct discussed in sociological and macro literature in that it is dependent on others' deference and approval. Reputation is defined as "the extent to which an organization is held in high esteem or regard” (Roberts \& Dowling, 2002: 1078), or “the consumer's subjective evaluation of the perceived quality of the producer" (Rhee \& Haunschild, 2006: 101). It is an expectation based on unobservable quality or other indiscernible traits that are generally difficult to quantify but are valued (Jensen \& Roy, 2008; Podolny, 1993; Washington \& Zajac, 2005). A 
typical example of a high-status prestigious leader would be a knowledgeable manager who is approached by others for her sound advice or help, or an emeritus professor who is admired and respected among other faculty members and sought out for his knowledge and expertise despite lacking institutional authority. Given the prevalence of both types of high-status actors in leadership positions, it has been theorized that dominance and prestige are two alternate forms of status broadly based on two discrete currencies (control versus respect).

Cheng et al. (2013) provide convincing empirical evidence of the above proposition. In one experiment, participants completed a task as part of a small group. Following the group exercise, participants rated each group member on his or her influence over the team outcome, as well as dominance or prestige behaviors associated with that person. Individuals who were perceived higher on either dominance or prestige were reported as more influential than others in the group but equally influential when compared to each other. Moreover, independent observers who viewed team members' interactions directed their attention (as measured through an eye tracker) more frequently towards those who were rated higher on either dominance or prestige (Cheng et al., 2013). In another context, an ethnographic study of Tsimane foragers in Bolivia's lowlands found that both dominance and prestige were associated with high status within the Tsimane community (von Rueden, Gurven, \& Kaplan, 2010). In summary, there is mounting evidence that one's status can be based either on dominance or prestige (Maner \& Case, 2016).

\section{Dominance, Prestige, and Attributions of Wrongdoing}

The idea that an actor's status plays a critical role in others' judgments, decisions, and behaviors towards them is not novel. A growing body of literature speaks to the dynamic rather than static nature of social status (Bendersky \& Shah, 2013; Hays \& Bendersky, 2015; Marr \& Thau, 2014; Pettit et al., 2013). For example, observers' status judgments for the same objective rank depend on whether the actor has risen or fallen to that rank within a social hierarchy (Pettit 
et al., 2013). Likewise, we contend that observers' judgments of actors' transgressions are not simply colored by the actors' overall status, but crucially depend on the type of status with which individuals are associated—specifically, whether their status is based on dominance or prestige. Further, building on third-party punishment literature in organizational and social justice research-whereby transgressors' characteristics influence both the attributions and the resulting punitive actions directed towards them (Malle \& Knobe, 1997; Skarlicki \& Kulik, 2004)—we argue that observers will ascribe different levels of punishment and intentionality judgments to dominant versus prestigious individuals for similar ambiguous misdeeds.

We reason that because individuals with high dominance-based status are associated with behaviors focused primarily on preserving their high-status position in the group without taking into consideration the goals and aspirations of other group members, their actions would generally be perceived as self-serving. Such individuals are also perceived as highly agentic, determined, and capable of taking decisive actions in comparison to their prestigious counterparts (Halevy et al., 2012; Kakkar \& Sivanathan, 2017; Laustsen \& Petersen, 2015). Integrating these two aspects of a high-status dominant actor (i.e., being self-serving and agentic), we contend that their ambiguous norm violation behavior will be considered intentional. Several studies demonstrate that dominant leaders act in ways that maintain their higher rank. For example, one study found that dominant leaders tend to ostracize or demote talented group members, and further withhold critical information to increase group members' dependence (Maner \& Mead, 2010). Moreover, such leaders restrict competent group members from bonding with others to reduce potential threats to their leadership position (Case \& Maner, 2014), and even allocate skilled employees to jobs unsuitable for the role (Maner \& Case, 2016). Thus, stereotypes of dominant leaders being perceived as highly agentic and driven by their 
personal goals will influence observers' judgments when evaluating their ambiguous norm violations, such that observers will attribute greater intentionality to their ambiguous misdeeds.

Further, attribution theorists have argued that "those who do negligent harm are judged less responsible than those who do intentional harm" (Darley \& Shultz, 1990: 533). For instance, workers were greeted with more punitive responses when their actions were believed to be intentional rather than accidental (e.g., pharmacists filling the wrong prescription or repairmen worsening the circuits of a television) (Shultz \& Wright, 1985). Similarly, a study investigating third-party punishments of norm violations found that intentional transgressions were punished more harshly, even at a cost to punishers, compared to identical misdeeds that lacked intentionality (Nelissen \& Zeelenberg, 2009). Consistent with this finding, Fragale et al. (2009) note that high-status actors are punished more severely for ambiguous transgressions than their low-status counterparts are, because their actions are perceived as more intentional. Further examination of these findings (Study 2) reveals their status manipulation to be more in line with dominance than prestige, as participants rated the high-status actor as more dominant, confident, selfish, less timid, and less submissive: attributes generally associated with high-status dominant individuals (Cheng et al., 2010; Maner \& Case, 2016). These results provide suggestive evidence that high-status dominant actors are likely to be punished more than other high-status actors for an ambiguous transgression because their ambiguous misdeed is perceived as intentional. Accordingly, we predict that increased attributions of intentionality will explain punishment directed towards the high-status dominant actors.

In contrast, individuals associated with prestige-based status are keenly sought for their advice and expertise and granted higher status for sharing their superior knowledge with others (Henrich \& Gil-White, 2001). Given that this status type is associated with helping others rather 
than promoting one's self-interests, prestigious individuals are perceived as having greater positive attributes and being more likeable (Cheng et al., 2010; Maner \& Case, 2016). For example, in comparison to their high-status dominant counterparts, high-status prestigious individuals are seen as more altruistic and cooperative (Halevy et al., 2012), less narcissistic, and more ethical, and enjoy broader social acceptability (Cheng et al., 2010). Thus, when accused of wrongdoing for an ambiguous norm violation where the transgression could theoretically be an honest mistake, individuals with prestige-based status are more likely to be given the benefit of the doubt. Observers are likely to judge their actions as less intentional and to not hold them accountable (cf. Bodenhausen \& Wyer, 1985; Fiske \& Neuberg, 1990). However, it is important to note that a simple positive stereotype may not always mitigate the impact of others' evaluation, as violating positive expectations can also lead to harsher punishment (Burgoon, 2015; Jussim, Coleman, \& Lerch, 1987; Rudman \& Fairchild, 2004). We explore this possibility in the general discussion part of our paper.

The other-oriented nature of prestige-based status means that it is accompanied by strong moral credentials. Moral credentials can serve as one mechanism that licenses norm violation behavior, or absolves individuals of such behavior (Miller \& Effron, 2010; Monin \& Miller, 2001). These credentials are granted based on one's virtuous behavioral history such that the subsequent norm violation is construed "as if it were not a transgression at all" (Miller \& Effron, 2010: 126). In this way, moral credentials allow others to construe the same ethical transgression as more acceptable than when the perpetrator lacks those credentials. For instance, in one study, a manager's ambiguous sexual overtures were not construed as sexual harassment when the manager had a history of supporting sexual harassment policies compared to when the behavior was unambiguous or such history was absent (Effron \& Monin, 2010). 
Since, individuals associated with prestige-based status are considered benevolent, helpful, and caring, which affords them greater moral credentials and buffers them from ambiguous misdeeds. Indeed, Polman et al. (2013) find that, compared to low-status actors, highstatus actors are punished less for ambiguous norm transgression, as their greater moral credentials cushion them against others retributive judgments. Notably, an examination of the status manipulation employed by Polman et al. (2013) reflects one based on prestige- the authors define status as "the respect, prestige, and admiration that individuals enjoy in the eyes of others" (p. 615). Thus, in the absence of unassailable evidence, prestigious leaders are given the benefit of the doubt because of their accumulated moral credentials and met with less severe punishment.

Similarly, in other studies where status was manipulated using job titles, those with highprestige jobs (e.g., surgeon, bank manager, etc.) were punished less in comparison to those with comparatively low-prestige jobs (e.g., dermatologist, convenience store clerk, etc.) (Loeffler \& Lawson, 2002; Rosoff, 1989). Again, these findings provide preliminary evidence in line with our theoretical assertion that high-status prestigious individuals are given the benefit of the doubt and punished less due to their accrued moral credentials. We therefore expect high-status prestigious actors to be punished less severely because of observers' reduced attributions of intentionality and increased perceptions of accumulated moral credentials in comparison to highstatus dominant actors.

In summary, we propose the following:

Hypothesis 1: When accused of an ambiguous transgression, a high-status actor will be punished more harshly if the actor's status is based on dominance rather than prestige.

Hypothesis 2: A high-status actor's ambiguous transgression will be perceived as more intentional if the actor's status is based on dominance rather than prestige. 
Hypothesis 3: A high-status actor will be granted greater moral credentials if the actor's status is based on prestige rather than dominance.

Hypothesis 4: Attributions of intentionality and moral credentials will mediate the relationship between actor's high-status based on dominance or prestige and severity of punishment for ambiguous transgression.

\section{OVERVIEW OF STUDIES}

Across three studies (and an additional three in the supplementary document), ${ }^{1}$ we demonstrate how an individual's status type (i.e., dominance versus prestige) shapes observers' judgments of the actor's transgressions. In Study 1, we first demonstrate the phenomenon within the real-world context of the National Hockey League (NHL) whereby high-status dominant players are punished more harshly than their prestigious counterparts. In Study 2, we manipulate the group leader's dominance and prestige behaviors to find that team members punish a dominant group leader more than a prestigious leader for ambiguous norm violation. Finally, in Study 3 , we independently manipulate both dominance- and prestige-based status to test the mechanisms behind the differential punishments directed at these leaders. Taken as a whole, our work provides a parsimonious account of the nuanced role of dominance- and prestige-based status in influencing the judgments and behaviors of third-party punishers.

\section{STUDY 1}

The goal of this study was to demonstrate our phenomenon of interest (hypothesis 1) in a real-world hierarchical setting. Specifically, we examined professional ice hockey players in the NHL and the minor penalties (punishment) handed down to them for infringing game rules (norm violation behavior). Though there are clear rules for awarding minor penalties, the judgment is often at the referee's discretion. Further, the referee must make this judgment in a split second after observing the incident from a potentially bad angle and without the benefit of video replay. Often minor penalties are incurred by players who have not deliberately committed

\footnotetext{
${ }^{1}$ See https://osf.io/9na53/
} 
a foul, highlighting the ambiguous nature of these incidents (Daniels, 2018; Ryan, 2017).

Additionally, the data we examined was collected after a major penalty rule change in the NHL that saw some offenses previously categorized as general penalties (e.g., clipping, charging, elbowing, etc.) upgraded to the major penalties category (NHL, 2014). This rule change further blurred the boundaries for calling out minor penalties (now based on a smaller set of infractions) in the subsequent NHL season.

Moreover, past research has shown that rule changes initially introduce noise to the decision-making process, and this is further compounded when decisions are made under time pressure (Edland \& Svenson, 1993). Both of these factors - ambiguity in judging a minor penalty and time pressure - leave open the possibility for referees' decisions to be influenced by a player's reputation. In fact, research has shown that referees' decisions are often influenced by players' or teams' reputations irrespective of the actual play (Jones, Paull, \& Erskine, 2002; Kim \& King, 2014; Johnston, 2018; Surowiecki, 2016). All of these aspects made the NHL a fitting real-world context to test our hypothesis.

We predicted that over the course of a season, with multiple incidents and decision points for referees to hand out minor penalties, the relationship between high-status prestigious players and the punishments awarded to them would be negative, whereas the relationship between highstatus dominant players and punishment would be positive.

\section{Sample}

We collected two years of NHL player-season-level data (2014-2016). The NHL season consists of 30 teams (23 U.S. and 7 Canadian) with each team playing 82 games, resulting in a 
total of 1,230 games. Our data comprised a total of 1,294 observations of player performance in a particular season with 756 unique players across the two seasons. ${ }^{2}$

\section{Measures}

\section{Dependent Variable}

Punishment. We measured punishment using minor penalties accrued by a player over the course of a season using penalty in minutes (PIM). PIM is an objective measure of minor penalties that indicates the total number of minutes a player was prohibited from taking part in the game (i.e., forced to leave the ice), leaving their team "short-handed" on the ice. Since the minor PIM data was aggregated at the season level, we normalized it by dividing by the total number of games a player participated over the course of a season.

\section{Independent Variables}

The two key independent variables were whether the player's status was based on dominance or prestige. To measure prestige-based status, it was essential to separate it from the overall status of the player. Hence, residuals obtained after regressing players' overall status on their performance were used to measure prestige (Apicella, 2014; Roberts \& Dowling, 2002). Dominance-based status was measured by interacting a physiological marker of dominance with a player's overall status, such that those with high status and the physical marker of dominance were considered to possess status based on dominance. Accordingly, we measured overall status, prestige, and dominance in this study but our hypothesis was limited to a player's status based on dominance or prestige.

Overall status. Status was operationalized as the current salary a given player was paid, as those with higher status are considered more competent and therefore paid more (Idson \& Kahane, 2000; Vincent \& Eastman, 2009). Moreover, salary has been used extensively in the

\footnotetext{
${ }^{2}$ We did not include goalkeepers, as a goalkeeper is hardly, if ever, awarded a penalty in the NHL.
} 
organizational literature as a marker of high status, as competent individuals/high performers are generally awarded higher salaries (Barron \& Waddell, 2003; Belliveau, O’Reilly, \& Wade, 1996; Bloom, 1999), especially in the context of professional sports (Harder, 1992; Scully, 1974).

Prestige. As discussed, prestige is essentially one's perceived reputation in the group, based on others' respect and admiration for their helpful on-ice play. Thus, we operationalized prestige similar to the reputation or deference measure used in past research by accounting for (i.e., partialling out) the variance based on a player's performance from the overall status measure, and utilizing those residuals as a measure of others' respect and deference (Apicella, 2014; Castellucci \& Ertug, 2010; Fombrun \& Shanley, 1990; Helou \& Park, 2001; Roberts \& Dowling, 2002).

Each player's reputation is a function of his objective performance and the intangible value he brings to the team by helping others and being a role model — a trait synonymous with high-status prestigious actors. To accurately measure prestige, it was thus essential to separate objective markers of performance from the unobservable ones (Apicella, 2014; Helou \& Park, 2001; Roberts \& Dowling, 2002). Sports analysts utilizing big data and high-end analytics advocate the use of advanced performance indicators that better capture the nuanced contributions made by a player within a team, such as Corsi. Corsi measures the collective impact an individual player has on a team by evaluating the scoring opportunities that his or her team experiences or the lack of scoring opportunities experienced by the opposing team, when the focal player is playing. Corsi is seen as having a better predictive validity in assessing the performance of a player compared to other measures of performance, such as goals, assists, or goal ratio (Likens, 2011; Macdonald, 2012). We therefore measured NHL players' past performance (i.e., each player's performance in the previous season) using Corsi. 
We then regressed each player's overall status (i.e., salary) for the current year on his past year's performance-Corsi and, controlling for the previous year's salary, his current salary relative to other members in the team and his age (as some players accrue reputation and more salary with increased years on a team). The regression residuals of salary obtained after accounting for a player's objective performance, relative salary, age, and previous year's salary were used as an operationalization of prestige. Thus, our measure of prestige was a conservative one, as we only captured unobservable factors after partialling out tangible factors that are often associated with prestige (e.g., relative salary and age). In short, the status that players were afforded beyond their objective performance and relative to others on the team was an indication of the intangible value they bring to the team in terms of their prestige.

Dominance. Following past research (Carré, McCormick, \& Mondloch, 2009; Haselhuhn, Ormiston, \& Wong, 2015; Mileva, Cowan, Cobey, Knowles, \& Little, 2014), we measured individuals' general tendency to be dominant using facial width-to-height ratio (fWHR); this is a physiological marker of dominance and not an indicator of whether one's status is based on dominance. We first describe fWHR as our operationalization for generalized dominance, followed by how we use fWHR to account for status based on dominance.

Several studies have shown that greater fWHR is an individual difference among men that is associated with both self and other rated trait dominance (Mileva et al., 2014), as well as with behaving aggressively (Haselhuhn et al., 2015) or being perceived as aggressive (Carré et al., 2009). Studies suggest that men with higher fWHR may possess greater concentrations of testosterone (Verdonck, Gaethofs, Carels, \& Zegher, 1999), a hormone that directly influences dominant tendencies and motivation to enhance one's status (Mazur \& Booth, 1998). Given the consistent set of findings that demonstrate a positive correlation between fWHR and trait 
dominance, we employed higher values of fWHR as a proxy for general dominant tendencies. fWHR is calculated by dividing bizygomatic width (i.e., the widest length of the face) with upper facial height (i.e., the length between the upper lip and brow) (Carré et al., 2009). To this end, we collected photographs of all players that participated in the 2014-2016 NHL seasons via the NHL official website (www.NHL.com) and standardized each image to the same format: 400X400 pixel size, similar color and intensity of background. Two independent coders who were unaware of the hypothesis measured the bizygomatic width and upper facial height of each player using an open source software, Image J. There was a high inter-rater agreement for facial height $(\alpha=.94)$, width $(\alpha=.97)$, and the overall fWHR $(\alpha=.91)$.

However, being dominant does not automatically lead to higher status. Rather, our theory suggests the effect to be accentuated for those who are dominant and have high status i.e. those associated with dominance-based status. Hence, we crossed fWHR with the overall status of the player and examined the interaction effect of dominance and status on punishment, such that players with high fWHR and high overall status will be punished the most. We contend that the higher values of interaction term of fWHR and status captures players with dominance-based status as they will typically be the ones associated with dominant tendencies and high status. Moreover, we find that salary and player performance were positively correlated, allowing us to use salary as a proxy for player performance $(b=.24, p<.001)$. We obtained identical results when we used performance (i.e., Corsi) as a measure of status.

\section{Control Variables}

We controlled for several factors that had the potential to influence our dependent variable, PIM. For instance, players' physical features (e.g., body weight) may result in greater punishment (Deaner, Goetz, Shattuck, \& Schnotala, 2012). Hence, we controlled for height, weight, body mass index (BMI), and age. We also controlled for PIM awarded in the previous 
season as a baseline measure of punishment for an individual player. Further, we controlled for (1) the position a player plays — forward (center, right wing, or left wing) or defense — as certain positions draw more penalties, (2) current performance using the Corsi measure, (3) players' experience, based on the year in which they were drafted, (4) shooting hand of the player, and (5) season fixed effects. Finally, we performed multilevel regressions with teams as the higher-level factor to partial out any variance due to team-level randomness; for example, some teams may prefer to play more aggressively and thus incur greater PIM. Table 1 presents means, standard deviations, and intercorrelations among variables.

------Insert Tables 1 and 2 here------

\section{Results}

Table 2 presents our multilevel regression results with PIM (punishment) as the dependent variable. Model 1 contains all control variables, followed by model 2, which contains prestige-based status, after controlling for overall status without any control variables. Model 4 reports the effect of dominance-based status as an interaction of generalized dominance (fWHR) and overall status while controlling for the main effect of both. Models 5 and 6 demonstrate the effect of prestige- and dominance-based status, respectively, after accounting for the control variables. Lastly, model 7 reports the effect of both prestige- and dominance-based status together after accounting for the control variables. In all of these models, we find that prestigebased status is negatively associated with punishment whereas dominance-based status is positively associated with the same. We report results here for model 7, as it includes both prestige- and dominance-based status. Prestige-based status was negatively associated with punishment $(b=-.02, S E=.009, p=.025)$, while the interaction term measuring dominancebased status was positively associated with punishment $(b=3.52, S E=.739, p<.001)$. 
On decomposing the interaction, at one standard deviation above and below values of status (Aiken \& West, 1991), we found that the slope with high values of status was positive and significant $(b=.80, S E=.15, p<.001)$, suggesting that high-status dominant players (i.e., those with higher generalized dominance coupled with high status) were punished more than those with lower generalized dominance (see the supplementary document for the interaction plot $^{1}$ ). Further, the slope for the interaction between low values of status and generalized dominance was also significant but negative $(b=-.45, S E=.15, p=.003)$, implying that those with low status and high dominance were punished less than those with low status and low dominance. The significant negative slope of the line when status was low was not one of our predictions, but warrants further investigation in future research. To directly test hypothesis 1 (i.e., to determine whether players with dominance-based status were punished more than those with prestige-based status), we compared the regression coefficients of the two. The regression coefficients were significantly different, $\left(\chi^{2}=22.93, p<.001\right)$, in support of hypothesis 1 .

It is important to note that support for hypothesis 1 might be sufficiently demonstrated by examining the main effect of prestige in comparison to dominance, but there can be instances when players' salaries do not efficiently reflect their overall performance. To account for those market inefficiencies and to examine parallels with our analysis based on dominance-based status, we interacted prestige with overall status and examined its effect on punishment (see Models 3, 8, and 9). The interaction effect of prestige and status on punishment was negative and significant $(b=-.21, S E=.05, p<.001$, Model 8$)$. Decomposing the interaction at one standard above and below the status values revealed that at high values of status, the slope was significant and negative $(b=-.06, S E=.01, p<.001)$, suggesting that as players' prestige increased, they were punished significantly less. The slope at low values of status was positive but marginally 
significant $(b=.02, S E=.01 p=.10)$, highlighting that prestige did not mitigate the impact of punishment when status was low (see the supplementary document for the interaction plot $^{1}$ ). Taken together, these results provide strong support for hypothesis 1 in a real-world context.

\section{Discussion}

Using the real-world context of the NHL, Study 1 helps document our phenomenon by providing an initial demonstration that high-status dominant actors were indeed punished more than high-status prestigious actors. These results present evidence of our central assertion that it is not simply the status of the transgressor that colors observers' judgment, but rather, the type of status they enjoy. Notwithstanding the strong evidence in favor of our hypothesis, this study only tested and found support for one of the four proposed hypotheses. Despite using minor penalties as the dependent variable, it is plausible that the mechanism behind these effects might not be based on intentionality or moral credentials. Thus, our inability to measure the psychological mediator is a limitation of this study. It is also important to note that we do not suggest that referees make their decisions based solely on players' facial dimensions. fWHR is one of many proxies used to capture the dominant tendencies of a player. Additionally, players' faces may sometimes be hidden from the referees, given the helmet and visors that players wear.

Moreover, one can never completely rule out endogeneity issues in archival studies. Despite controlling for a number of variables and employing a conservative approach to our measures and operationalization, there is the possibility of other unobservable or unmeasured variables confounding our results. Another criticism that could be levied against the current study is a need to measure our constructs using validated measures or manipulations of dominance or prestige that more precisely capture our variables of interest - that is, the interaction between fWHR and overall status may not account for all of the variance associated with dominance-based status. Hence, in the studies that follow, we manipulate dominance and 
prestige using existing manipulations in the literature to ensure that the operationalization of our central variables mirrors the theoretical assertion of the two status types.

\section{STUDY 2}

The objective of Study 2 was to replicate the findings from Study 1 by manipulating leader behavior either in terms of dominance or prestige, thereby providing greater causal evidence. In addition, we wanted to mirror the social interactions within organizations where team members interact to resolve a task. We sought to achieve this aim by having individuals work within a team to accomplish a clear task - a protocol similar to other experiments designed to manipulate status among teams (Anderson \& Kilduff, 2009; Cheng et al., 2013). Specifically, we ran a study where participants engaged in a group activity and, unknown to the participants, we manipulated the group leader's dominant or prestigious behavior by bringing in a confederate. Following this interaction, participants engaged in an individual task designed to examine their reaction towards their group leader after an ambiguous norm violation. In line with our hypothesis, we expected participants to take harsher punitive actions against the leader in the dominance condition than in the prestige condition.

\section{Sample and Procedure}

Participants. We decided to recruit at least 150 participants to ensure an adequate number of participants and groups. Accordingly, 160 participants took part in the study, recruited via the behavioral lab of a European business school; however, eight participants did not follow the study protocol or were suspicious about the confederate and were removed from the final analysis. The final sample consisted of 152 participants $\left(M_{\text {Age }}=30.30\right.$ years, $S D_{\text {Age }}=12.95$, $57.9 \%$ females) of which 73 were in the prestige condition and 79 in the dominance condition. These participants were part of 38 distinct work groups that ranged from three to six members per group, including the actor. We aimed for at least four members in each group but due to last- 
minute cancellations, we were left with six groups that included only three members. Our results remain identical even if these groups are excluded.

Procedure. To ensure our study was high on both internal and external validity, we ran a study protocol similar to Cheng et al. (2013). The protocol consisted of two parts, which we discuss in extensive detail below (see Figure S5 in the supplementary document for schematic diagram of the study's protocol) ${ }^{1}$. In the first part, participants attempted a task individually and then performed the same task as a group, which gave them an opportunity to evaluate whether their group leader was high in terms of dominance or prestige. The second part of the study was carried out in individual cubicles where participants learned about an ambiguous norm violation committed by their group leader and were then given an opportunity to punish him (the leader was always a male associate acting as a participant).

Upon entering the lab, participants attempted a "Lost at Sea" task (Nemiroff \& Pasmore, 2001), which required them to rank order 15 items (e.g., a sextant, a shaving mirror, etc.) in order of their importance for survival on a deserted boat awaiting rescue. Participants had 15 minutes to submit their private rankings. Participants then worked as a group on the same task, where they discussed the benefits of each item and submitted one ranking as a group. Before starting the group activity, participants were randomly assigned to the role of either a team member or a leader using a lottery draw. However, unknown to them, the lottery draw was rigged to ensure that the confederate was always chosen as the leader. The confederate was a professional actor, who was trained by the experimenters to display typical behavioral cues associated with either dominance-based status or prestige-based status (e.g., adapting more expansive postures when behaving dominantly as opposed to prestigiously, interrupting and speaking more in the dominance condition compared to being helpful and supportive in the prestige condition (Cheng 
et al., 2013), modulating vocal pitch by speaking in a deeper tone in the dominance condition (Cheng, Tracy, Ho, \& Henrich, 2016), etc.). Following the training, the actor participated in mock sessions to get comfortable with the role by enacting both behaviors.

After submitting rankings of the 15 items as a group, participants were directed into individual cubicles for the second part of the study, which consisted of two stages. In the first stage, participants learned about the group leader's alleged norm violation behavior against another anonymized group member. The second stage involved focal participants having the opportunity to punish the group leader by assigning him harder questions as part of a general ability task.

In the second part of the study, participants learned that they would either take part in an economic game with another participant or attempt a general ability task with an opportunity to earn extra money. The general ability task was supposed to start after the economic game and, if participants were selected for the general ability task, they would have to wait as another participant from the economic game task would be paired randomly with them. To compensate for their waiting time, participants had the opportunity to choose the difficulty level of the general ability task for themselves and their partner. In reality, all participants were assigned to the general ability task and had to wait until the hypothetical economic game between the other two participants finished.

Participants engaged in a filler activity while they waited for the general ability task to begin. After completing the filler activity, they read the rules of the supposed economic game that took place between the two other group members. It was a dictator game where the offerer had the opportunity to split $£ 5$ in any way between himself/herself and the receiver. However, participants were explicitly informed that the norm was to split the amount equally. Offerers and 
receivers would then be paid according to the allocation. Nonetheless, there was a $30 \%$ chance that a computer algorithm may overrule the offerer's decision by splitting the amount randomly between the two parties. Since the algorithm could potentially decide the final allocation, it created a sense of ambiguity around the offerer's decision. After the final allocation, the receiver had the opportunity to comment about his/her interaction with the partner.

Participants then learned about the ostensible economic transaction that happened between the offerer and receiver. They learned that the group leader played the role of offerer and another group member was the receiver. Participants then read the statement from the receiver of the economic transaction about his/her experience in the economic game, which stated: “Group leader took less than 5 seconds to decide, kept a substantial amount of money for himself, and transferred practically nothing." This message revealed that the group leader violated the norm of splitting the money evenly.

Next, participants started the general ability task and learned they were paired with the group leader, who played the role of offerer in the economic game. Participants first attempted two trial questions and were informed that solving each question would lead to a reward of $£ .10$. The questions required finding two numbers that add up to 10 in a $3 X 3$ matrix within 15 seconds (cf. Mazar, Amir, \& Ariely, 2008). After attempting two trial questions of moderate difficulty, participants were given the opportunity to choose a total of four questions for their partner, the group leader, from the eight available choices, of which four were easy and four difficult. Similar to above, any question answered correctly by the group leader would result in a reward of $£ .10$ for him. Thus, assigning hard questions to the leader had tangible monetary ramifications for the leader. The total number of difficult questions assigned to the group leader was operationalized to measure punishment. Participants then rated the group leader on a validated seven-point Likert 
scale of dominance and prestige (Cheng et al., 2010), (1 = not at all, $4=$ somewhat, $7=$ very much; sample item for dominance, "Group leader tried to control other members rather than permit them to control him/her," $\alpha_{\text {Dom }}=.86$; sample item for prestige, "Group leader was respected and admired by other members", $\left.\alpha_{P t g}=.91\right)$. Finally, participants submitted their demographic details, received compensation for their participation, and were debriefed.

\section{Results}

Manipulation check. Participants reported the group leader higher on dominance than prestige in the dominance condition, $t(156)=2.68, p=.008,\left(M_{D o m}=3.99, S D=1.25, M_{P t g}=\right.$ $3.46, S D=1.24)$ and higher on prestige than dominance in the prestige condition, $t(156)=2.68$, $p=.008,\left(M_{P t g}=3.76, S D=1.32, M_{\text {Dom }}=3.27, S D=1.20\right)$. These results indicated that our manipulation worked as intended. We also inspected whether the leader's influence was similar across the two conditions since both status types should be equally influential (Cheng et al., 2013). Consistent with past research, we found that there were no significant differences in private and group rankings for any of the 15 items $(p>.05)$ across the two conditions, suggesting that the leader was equally persuasive and influential in swaying group members' initial private rankings across the two conditions. In short, our manipulation worked as intended.

Insert Table 3 here

Punishment. A one-way ANOVA was significant across the two conditions, $F(1,150)=$ $4.80, p=.03$ (see Table 3), such that the group leader was assigned a greater number of hard questions in the dominance condition than in the prestige condition $\left(M_{D o m}=1.86, S D=.75, M_{P t g}\right.$ $=1.60, S D=.70)$. Since participants were nested within groups, we also performed a multilevel regression analysis by coding dominance condition as 1 and prestige condition as 0 , with groups as the higher-level factor, controlling for the total number of participants in groups and their key demographics (age, gender). In support of our hypothesis, we again found that the dominance 
condition was significantly correlated with punishment compared to prestige $(b=.32, p=.01)$ (see Table S1 in the supplementary document ${ }^{1}$ ). Overall, by experimentally manipulating dominance and prestige, we found causal support in favor of hypothesis 1.

\section{Discussion}

The goal of this study was to replicate the findings of Study 1 by experimentally manipulating the dominance- and prestige-based status of a leader. In addition, we demonstrate the robustness of our hypothesized effects using a behavioral measure. To ensure greater external validity, we replicated these effects within the context of a group activity that mirrored tasks one could expect to encounter within an organizational context. By manipulating the leader's dominance or prestige using real groups, this study provides greater assertion of causality. The next study tests the psychological mechanisms driving our effects.

\section{STUDY 3}

Study $3^{3}$ was designed to test the two psychological mechanisms of intentionality and moral credentials. Additionally, we also wanted to examine if greater dominance (prestige) leads to higher (lower) punishment recommendations or an interaction of both. To test these possibilities, we manipulated the dominance- and prestige-based status of the focal actor independently. Thus, the high-status individual in the scenario was either described as high or low on each of the two status dimensions. To further the generalizability and robustness of our findings, we employed two scenarios: one directly adapted from prior research where a CEO of a Fortune 500 company was accused of tax fraud (Fragale et al., 2009), and the other a recruitment scenario involving a senior vice president of a Fortune 500 company (cf. Polman et al., 2013). We focused on senior leaders (i.e., CEO or VP) as senior leadership positions are associated with

\footnotetext{
${ }^{3}$ Three additional studies demonstrate the robustness of our findings by measuring dominance and prestige, ruling out alternate explanations of liking, transgressor's gender, competence, perceived power, and testing the complete model (see the supplementary document https://osf.io/9na53/).
} 
high status. We then varied the status type by describing the leader as high or low in dominance or prestige.

\section{Method}

Participants. We collected a large sample to ensure that we could reliably detect any interaction between dominance and prestige. We recruited 498 participants via Amazon Mechanical Turk (MTurk), of which three participants were excluded for taking the study more than once, and another four were excluded for failing the attention check question. Thus, the final sample consisted of 491 participants $\left(51.12 \%\right.$ females, $M_{\text {age }}=35.55$ years, $\left.S D_{\text {age }}=11.30\right)$.

Design and procedure. Our study used a between-subjects design. Participants were randomly assigned to one cell within a 2 (dominance: high $(\mathrm{n}=246)$ versus low $(\mathrm{n}=245))$ X 2 (prestige: high $(\mathrm{n}=245)$ versus low $(\mathrm{n}=246))$ X 2 (scenarios: CEO or VP) matrix. In the highdominance condition, ${ }^{4}$ the CEO or VP (who was male in every scenario) was described as controlling and dominating with his colleagues, whereas in the low-dominance condition, he was described as not being dominant or controlling. Similarly, in the high-prestige condition, the CEO or VP was described as being respected and admired by his colleagues, whereas in the lowprestige condition, he was described as not being respected or admired. The order of dominance and prestige was counterbalanced. Following this, participants were randomly assigned to one of the two ambiguous transgression scenarios. One scenario was directly adapted from prior research (Fragale et al., 2009). Specifically, participants read the following:

Recently, the Internal Revenue Service (IRS) accused K. Wallace of underpaying the federal government on his personal income taxes. Over the past few years, federal tax laws have become increasingly complex, and there are now more rules and regulations than ever before. Over this same period of time, the IRS has documented a substantial rise in improper tax returns. Some are a result of simple mistakes, while others are deliberate attempts to pay lower taxes. Although official charges have not been filed

\footnotetext{
${ }^{4}$ The manipulations were pretested with a different sample; see Study S2 in the supplementary document.
} 
against $K$. Wallace, the IRS alleges that $K$. Wallace's tax return understated the amount of money that he owed to the federal government.

The other scenario described a senior white vice president in a Fortune 500 company overseeing a new recruitment, who did not hire a suitable African American candidate (cf. Polman et al., 2013). Specifically, participants read the following:

Recently, an African American candidate who gave a recruitment interview to Eric Jones in response to the job opening advertisement accused Jones of racial discrimination. The candidate argued that he had over 10 years of experience and was well suited for the job but was passed on because of his skin color. In response, Eric Jones released a statement saying there were several well-qualified candidates and he chose the one that was most suitable for the job. Although official charges have not been filed against Eric Jones, the candidate is exploring legal options for being denied the job.

After learning about either of the two ambiguous transgression, participants responded to the following dependent variables. Punishment was measured by asking participants how harshly they would punish the actor and whether a legal case should be filed against him $(\alpha=.90)$.

Moral credentials were measured using a composite of three items assessing how moral, wrong, and unethical his behavior was $(\alpha=.87)$ (cf. Polman et al., 2013). Intentionality was measured using a single item that asked how strongly participants felt that the behavior was deliberate (cf. Fragale et al., 2009). Participants also responded to a single-item manipulation check assessing the actor's overall status.

\section{Results}

Manipulation check. The manipulation check on status worked as intended $(F(1,487)=$ $\left.6.08, p=.014, \eta^{2}=.01\right)$. The actor was afforded the highest status when both dominance and prestige were high $(M=6.07, S D=1.19)$ and least when both were low $(M=4.04, S D=1.88)$, with intermediate status conferred when either of dominance $(M=5.44, S D=1.44)$ or prestige was high $(M=5.36, S D=1.50)$ (see the supplementary document for further details $\left.{ }^{1}\right)$. 
Punishment. We performed a 2 (dominance: high versus low) X 2 (prestige: high versus low) ANOVA with punishment judgments as the dependent variable. ${ }^{5}$ The actor was punished more when dominance was high $(M=3.86, S D=1.82)$ compared to when it was low $(M=3.25$, $S D=1.71, F(1,487)=15.31, p<.001, \eta^{2}=.03$, see Table 4). Conversely, punishment was significantly less when the actor was rated high on prestige $(M=3.09, S D=1.70)$ than low $(M=$ 4.02, $\left.S D=1.76), F(1,487)=36.47, p<.001, \eta^{2}=.07\right)$. We did not observe any interaction effect $(F(1,487)=.29, p=.60)$. Since our hypothesis is a comparison of prestige- versus dominancebased status, we compared the means in the high-dominance low-prestige cell to those in the low-dominance high-prestige cell. The means were significantly different such that the actor in the former cell was punished significantly more $(M=4.28, S D=1.79)$ than the actor in the later cell $(M=2.75, S D=1.59, t(245)=7.1, p<.001)$, thus supporting hypothesis 1 .

Intentionality. A similar pattern was observed for attributions of intentionality and main effects of both dominance $\left(F(1,487)=16.10, p<.001, \eta^{2}=.03\right)$ and prestige $(F(1,487)=43.0, p$ $\left.<.001, \eta^{2}=.08\right)$, but no interaction $(F(1,487)=.02, p=.89$, Table 3). The transgression was considered significantly more intentional in the high- $(M=3.86, S D=1.95)$ as opposed to the low- $(M=3.19, S D=1.84))$ dominance condition. Conversely, such actions were perceived as less intentional in the high- $(M=2.98, S D=1.77)$ rather than the low- $(M=4.07, S D=1.92)$ prestige condition. Further, when comparing the two incongruent cells of high-dominance lowprestige to low-dominance high-prestige, intentionality was judged to be significantly greater in the former cell $\left(M_{1}=4.40, S D_{1}=1.93, M_{2}=2.67, S D_{2}=1.66, t(245)=7.55, p<.001\right)$. Overall, hypothesis 2 was supported.

\footnotetext{
${ }^{5}$ We performed a series of three- and four-way interactions, including the order of the transgression scenarios and status type along with the two main manipulations for all the reported variables. None of these interactions were significant.
} 
Moral credentials. Consistent with our expectations, we observed main effects of both dominance $\left(F(1,487)=4.51, p=.034, \eta^{2}=.01\right)$ and prestige $\left(F(1,487)=42.18, p<.001, \eta^{2}=\right.$ $.08)$ on moral credentials, but no interaction $(F(1,487)=.28, p=.60$, Table 3$)$. Participants in the high-dominance condition bestowed lower moral credentials $(M=3.78, S D=1.76)$ than participants in the low-dominance condition $(M=4.11, S D=1.76)$. Conversely, participants assigned to the high-prestige condition were afforded greater moral credentials $(M=4.44, S D=$ 1.73) than participants in the low-prestige condition $(M=3.45, S D=1.66)$. Comparing the two incongruent cells, we find that participants assigned to the high-dominance low-prestige condition were afforded significantly less moral credentials than participants assigned to the lowdominance high-prestige condition $\left(M_{1}=3.32, S D_{1}=1.63, M_{2}=4.64, S D_{2}=1.68, t(245)=6.22\right.$, $p<.001)$, thus supporting hypothesis 3 .

Mediation analysis. We performed bootstrap mediation analysis using structural equation modeling by comparing participants' responses in the high-dominance low-prestige cell with those of participants in the low-dominance high-prestige cell. We coded dominance as 1 and prestige as 0 . Intentionality and moral credentials were included as two parallel mediators and punishment as the dependent variable (see Figure 1). A significant indirect effect of dominance compared to prestige via intentionality on punishment was observed $(b=.86, S E=.17, p<.001$, $95 \% C I[.56,1.20])$. Further, in comparison to prestige, the indirect effect of dominance on punishment via a lack of moral credentials was also significant $(b=.56, S E=.14, p<.001$, $95 \% C I[.32, .89])$. The total indirect effect on punishment via the two mediators was positive and significant $(b=1.42, S E=.19, p<.001,95 \% C I[1.05,1.79])$. After accounting for the indirect effect, the direct effect on punishment became insignificant $(b=.12, S E=.12, p=.34,95 \% C I[-$ $.12, .35])$. Overall, hypothesis 4 was supported. 
As an additional analysis, we also examined whether the indirect effect of high dominance (prestige) in comparison to low dominance (prestige) was also significant via the two mediators. We found that both the indirect effects were significant, suggesting that the two status types independently influenced punishment judgments via intentionality and moral credentials, such that high dominance (in comparison to low dominance) led to greater punishment while high prestige (in comparison to low prestige) resulted in lower sanctioning (see the supplementary document for further details ${ }^{1}$ ).

\section{-------- Insert Table 4 and Figure 1 here --------}

\section{Discussion}

By manipulating dominance and prestige, we find that both status types influence observers' punishment judgments, such that greater dominance leads to higher punishment and greater prestige results in lower punishment. Further, there was no interaction, suggesting that the two status types independently influence observers' judgments. Importantly, Study 3 replicated our findings from previous studies and tested the complete model, highlighting the pivotal role that attributions of intentionality (Fragale et al., 2009) and moral credentials (Polman et al., 2013) play in explaining the harsher punishments meted out to dominant high-status actors. Moreover, by including two different transgression scenarios, this study further demonstrates the generalizability and robustness of our findings across different contexts.

\section{GENERAL DISCUSSION}

When high-status actors are associated with ambiguous norm and moral violations, predictions of whether they would be punished or not, have to date, been based on very mixed evidence. At times, high status appears to attenuate the severity of punishment doled out by third-party observers, while at other times, it appears to have the opposite effect. We set out to 
reconcile these contradictory findings by investigating why and how the same social marker of status can yield such disparate reactions.

We hypothesized that observer judgments will depend critically on the status type of high-status actors - specifically, whether their status is based on prestige or dominance. Across three studies (and an additional three in the supplementary document ${ }^{1}$ ) that span archival field data, lab experiments, and experimental scenarios, we consistently find that for similar ambiguous misdeeds, high-status individuals associated with dominance were punished more harshly than those whose status was based on prestige. Transgressions of high-status dominant actors were perceived as intentional and associated with a lack of moral credentials compared to similar misdeeds of high-status prestigious leaders. By conceptualizing and measuring two different status type, our research offers a more nuanced and parsimonious account of the vital role that status plays in the attributions and punishment others direct towards high-status transgressors.

\section{Theoretical Contributions}

Our research makes several important theoretical contributions. First, by drawing on the two evolutionary bases of social status, our results provide a theoretically sound explanation for why ambiguous transgressions of high-status leaders are perceived as more offensive than similar misdeeds of other high-ranked actors. In doing so, this work goes beyond the broad assessment of having high versus low status, to highlight the importance of status type as a critical factor in coloring observers' assessments of transgression. Our findings imply that organizational leaders commanding similar high status may yet have differential exposure to the risk of being targeted for ambiguous norm violations.

Second, by discussing two different types of social status (i.e., dominance and prestige) rather than simply evaluating on the basis of overall status, our work reconciles inconsistent 
findings in the literature. We demonstrate that intentionality and moral credentials are not two different psychological accounts for the same phenomenon, but that both these mechanisms operate in tandem to influence punishment judgments depending on the transgressor's status type. Furthermore, results from Studies 1 and 3 suggest that high-status dominant actors are punished more in comparison to low-status actors, whereas high-status prestigious individuals are punished less than low-status individuals. Though it was not the primary aim of this paper to examine punishment differences between low-status actors and high-status actors based on dominance or prestige, the consistent findings to this effect obtained in Studies 1 and 3 form a useful contribution to the status literature.

Third, we find that ambiguous transgressions by high-status dominant actors are perceived as more intentional than those of their prestigious counterparts, which in turn explains the harsher punishment doled out to the former. These findings contribute to the research on retributive justice (Darley \& Pittman, 2003) where reactions to wrongdoings — by jurors in a courtroom, by employee supervisors, or by the general public-rely on intentionality judgments as the proximal driver of punishment.

Fourth, organizational scholars repeatedly call for a stakeholder perspective to the governance of firms and the behaviors of those within (Donaldson \& Preston, 1995; Kochan \& Rubinstein, 2000). Our research contributes to this dialogue by examining transgressions of highstatus organizational actors from a third party's viewpoint, a perspective that "has received relatively little research attention" in organizational research (Skarlicki \& Kulik, 2004: 218). More importantly, in line with the authors' theoretical model, we find that transgressor characteristics (e.g., status type) influence attributions of blame/intentionality, which then mediate the "comeuppances" levied at the transgressor. Moreover, since the third-party observers 
were not directly affected by the transgressor's actions in our tests, our findings suggest that not all punitive actions aimed at restoring justice are based on the dominant narrative of self-interest (cf. Miller, 1999), but can also be guided by safeguarding normative moral standards.

Fifth, our findings parallel those of McDonnell \& King's (2018) firm-level report, which found that prestigious organizations (i.e., those high in terms of both status and domain-specific reputation) were less likely to be blamed for a transgression. The authors argued that positive expectations associated with such firms lead third-party evaluators to expect that their behavior is appropriate when guilt is not established. Notably, although they were theoretically asserted, these positive expectations were not explicitly measured. Our findings not only replicate these findings at the individual level but also test the mechanism of attributing less blame to prestigious actors' transgressions. However, McDonnell \& King (2018) also found that once guilt was established for a prestigious organization, it incurred severe punishment; we delve on this finding in the section below.

\section{Limitations and Future Directions}

As discussed, a possible limitation of our research could be contingency factors such as the nature of the transgression, or observer identification with the high-status transgressor that could potentially moderate the main effect of status type on punishment. Further, our findings indicate that the greater the moral credentials conferred to those who help, advise, and share valuable information (i.e., prestigious leaders), the more these credentials buffer such leaders from third-party punishments. A related and parallel finding based on accrued moral credentials is that of moral self-licensing (Monin \& Miller, 2001). The central findings here are that past moral actions liberate an individual (i.e., allow one to grant self-license) to indulge in less moral deeds. Thus, if past good deeds by prestigious leaders earn moral credentials, are these leaders 
also more vulnerable to indulging in morally questionable behavior in the future due to selflicensing? This intriguing possibility warrants future investigation.

Our findings paint a rosy picture for high-status prestigious leaders that suggests they would be invariably excused for ambiguous transgressions. However, it is plausible that when high-status prestigious actors engage in transgressions that are central to their identity or antithetical to the process (sharing of skills, knowledge, etc.) that garnered them status, they will be punished more harshly. For example, Governor of New York Eliot Spitzer was lauded for his dogged fight against sex trafficking and prostitution. When accused of soliciting prostitutes, he was therefore subjected to extreme criticism and ridicule, and forced to resign (Hakim \& Santos, 2008). In this way, violating the specific principles that one's prestige is based on may result in perceptions of hypocrisy and harsher judgments, in line with expectancy and stereotype violation theory (Burgoon, 2015; Rudman \& Fairchild, 2004). Consequently, such hypocrisy penalty might explain our discontent and visceral reactions towards those who are found violating the very standards they were once applauded for. The above proposition is in line with McDonnell and King's (2018) firm-level findings where prestigious organizations were reprimanded more for transgressions where their blameworthiness was established.

Our findings are also relevant to the trust repair literature examining reactions to competence or integrity-based transgressions (Kim, Dirks, Cooper, \& Ferrin, 2006; Kim, Ferrin, Cooper, \& Dirks, 2004). It is plausible that high-status prestigious actors compared to their dominant counterparts would be punished more for violating ethical or integrity-based trust, as dominant individuals are expected to behave in such manner and hence tolerated more compared to high-status prestigious actors who are not expected to partake in such behaviors. Thus, it would be informative to explore how certain type of trust violations may moderate our results. 


\section{Practical Implications}

These results also carry various practical implications. First, in an age of hyper-vigilant media, a common challenge for executives is crisis management (Diermeier, 2011; Pearson \& Clair, 1998). Crises range from corporate fraud to allegations of sexual harassment to environmental violations and more. Suddenly, leaders can be catapulted into the media as the face of their organization and are expected to manage the situation. For instance, Tony Hayward, CEO of BP, was cast into the role of main representative during BP's disastrous oil spill, and was the target of public scorn. Contrastingly, James Burke, CEO of Johnson \& Johnson during the Tylenol crisis of 1982, was not only forgiven in the court of public opinion but was applauded for his handling of the situation. Our findings indicate that these differential public reactions could have much to do with how leaders are perceived. Given the differences in attributions of intentionality and moral credentials that we assign to dominant versus prestigious leaders, it is critical for organizations to evaluate the type of leader they would most prefer as the face of the company during a crisis.

Our results also suggest a dominant CEO is more likely to be held accountable for the crisis compared to a prestigious CEO. For instance, Nike's employment practices were subjected to huge criticism when it emerged that some managers behaved in a dominant and aggressive manner towards their employees. Several employees were reported to have fainted when a manager forced them to run multiple laps around the company perimeter as punishment for not reaching their production targets. When this news reached the public, it led to a sharp drop in Nike's sales and stock price (Saporito, 1998). In these situations, an obvious solution would be to disassociate with dominant CEOs or managers in order to safeguard a firm's reputation. However, in instances where distancing from an accused leader is not a viable option, organizations should make sure that they provide timely and appropriate communications 
explaining their behavior or apologizing for their conduct. Providing relevant justification and apologizing for inappropriate conduct have been shown to reduce backlash against the guilty party (Darley \& Pittman, 2003). For example, when a white Starbuck's manager acted prejudicially towards a black customer in a store at Philadelphia, in response to the ensuing backlash, its CEO apologized, accepted the fault, and voluntarily initiated racial bias training to all of its employees across 8,000 stores with a promise to evaluate its impact. This action was acknowledged as a positive first step in responding to a misconduct that could have easily derailed the company's sales and credibility (Salmon, 2018).

Finally, from a policy and legal perspective, these results create a perverse incentive for prestigious leaders. If leaders are aware of their prestige, they may be encouraged to hide their misdeeds, instead of taking corrective actions, knowing that they are less likely to be held accountable. This is an important issue as both these factors - greater incentive to cheat (Harris \& Bromiley, 2007) and being a member of a prominent and reputable firm-have been associated with a greater likelihood of violating moral standards (Mishina, Dykes, Block, \& Pollock, 2010). Additionally, the tendency to levy different intentionality attributions for similar misdeeds based on the transgressor's status type poses a challenge for policymakers, lawyers, and members of juries who seek to impart fair punishment and justice to the violators (see Carlsmith \& Darley, 2008, for a review). It is imperative that such observers become aware of these factors before arriving at a verdict.

\section{Conclusion}

Geithner, despite clear evidence of tax avoidance, rose in the U.S. political hierarchy. Daschle, following similar evidence of tax avoidance, suffered a precipitous drop in his political career. Our set of studies provides an evidence-based explanation for why two similarly highstatus actors, accused of similar misdeeds, experienced such different outcomes. Further, and 
more importantly, by exploring the particular status type associated with a high-status actor

(dominance or prestige), our findings help to resolve existing inconsistencies in the literature. In doing so, we advance our theoretical understanding of when and how the much sought-after commodity of status can act as a premium or a liability to its bearer.

\section{REFERENCES}

Aiken, L. S., \& West, S. G. 1991. Multiple regression: Testing and interpreting interactions, vol. XI. Thousand Oaks, CA: Sage Publications, Inc.

Anderson, C., \& Brown, C. E. 2010. The functions and dysfunctions of hierarchy. Research in Organizational Behavior, 30: 55-89.

Anderson, C., \& Kilduff, G. J. 2009. Why do dominant personalities attain influence in face-toface groups? The competence-signaling effects of trait dominance. Journal of Personality and Social Psychology, 96(2): 491-503.

Apicella, C. L. 2014. Upper-body strength predicts hunting reputation and reproductive success in Hadza hunter-gatherers. Evolution and Human Behavior, 35(6): 508-518.

Báles, R. F., Strodtbeck, F. L., Mills, T. M., \& Roseborough, M. E. 1951. Channels of Communication in Small Groups. American Sociological Review, 16(4): 461-468.

Barron, J. M., \& Waddell, G. R. 2003. Executive rank, pay and project selection. Journal of Financial Economics, 67(2): 305-349.

Belliveau, M. A., O'Reilly, C. A., \& Wade, J. B. 1996. Social Capital at the Top: Effects of Social Similarity and Status on CEO Compensation. Academy of Management Journal, 39(6): 1568-1593.

Bendersky, C., \& Shah, N. P. 2013. The Downfall of Extraverts and Rise of Neurotics: The Dynamic Process of Status Allocation in Task Groups. Academy of Management Journal, 56(2): 387-406.

Berger, J., Cohen, B. P., \& Zelditch, M. 1972. Status Characteristics and Social Interaction. American Sociological Review, 37(3): 241.

Berger, J., Rosenholtz, S. J., \& Zelditch, M. 1980. Status Organizing Processes. Annual Review of Sociology, 6: 479-508.

Bloom, M. 1999. The Performance Effects of Pay Dispersion on Individuals and Organizations. Academy of Management Journal, 42(1): 25-40.

Bodenhausen, G. V., \& Wyer, R. S. 1985. Effects of stereotypes on decision making and information-processing strategies. Journal of Personality and Social Psychology, 48(2): 267-282.

Bowles, H. R., \& Gelfand, M. 2009. Status and the Evaluation of Workplace Deviance. Psychological Science, 21(1): 49-54.

Brown, C. B. 2009, February 2. Daschle: Mistakes were "unintentional." Politico. https://www.politico.com/news/stories/0209/18290.html.

Burgoon, J. K. 2015. Expectancy Violations Theory. The International Encyclopedia of Interpersonal Communication. John Wiley \& Sons, Inc. https://doi.org/10.1002/9781118540190.wbeic102. 
Calmes, J. 2009, January 26. Senate Confirms Geithner for Treasury Post. The New York Times. https://www.nytimes.com/2009/01/27/us/politics/27geithner.html.

Carlsmith, K. M., \& Darley, J. M. 2008. Psychological Aspects of Retributive Justice. Advances in Experimental Social Psychology, 40: 193-236.

Carré, J. M., McCormick, C. M., \& Mondloch, C. J. 2009. Facial Structure Is a Reliable Cue of Aggressive Behavior. Psychological Science, 20(10): 1194-1198.

Case, C. R., \& Maner, J. K. 2014. Divide and conquer: When and why leaders undermine the cohesive fabric of their group. Journal of Personality and Social Psychology, 107(6): 1033-1050.

Castellucci, F., \& Ertug, G. 2010. What's in It for Them? Advantages of Higher-Status Partners in Exchange Relationships. Academy of Management Journal, 53(1): 149-166.

Cheng, J. T., Tracy, J. L., Foulsham, T., Kingstone, A., \& Henrich, J. 2013. Two ways to the top: Evidence that dominance and prestige are distinct yet viable avenues to social rank and influence. Journal of Personality and Social Psychology, 104(1): 103-125.

Cheng, J. T., Tracy, J. L., \& Henrich, J. 2010. Pride, personality, and the evolutionary foundations of human social status. Evolution and Human Behavior, 31(5): 334-347.

Cheng, J. T., Tracy, J. L., Ho, S., \& Henrich, J. 2016. Listen, follow me: Dynamic vocal signals of dominance predict emergent social rank in humans. Journal of Experimental Psychology: General, 145(5): 536-547.

Daniels, C. 2018, May 10. NHL officiating is beyond bad in playoffs. Yorkton This Week. http://www.yorktonthisweek.com/opinion/columnists/nhl-officiating-is-beyond-bad-inplayoffs-1.23296943.

Darley, J. M., \& Pittman, T. S. 2003. The Psychology of Compensatory and Retributive Justice. Personality and Social Psychology Review, 7(4): 324-336.

Darley, J. M., \& Shultz, T. R. 1990. Moral Rules: Their Content and Acquisition. Annual Review of Psychology, 41(1): 525-556.

Deaner, R. O., Goetz, S. M. M., Shattuck, K., \& Schnotala, T. 2012. Body weight, not facial width-to-height ratio, predicts aggression in pro hockey players. Journal of Research in Personality, 46(2): 235-238.

Devine, D. J., \& Caughlin, D. E. 2014. Do they matter? A meta-analytic investigation of individual characteristics and guilt judgments. Psychology, Public Policy, and Law, 20(2): 109-134.

Diermeier, D. 2011. Reputation rules: Strategies for building your company's most valuable asset. New York: McGraw Hill Professional.

Donaldson, T., \& Preston, L. E. 1995. The stakeholder theory of the corporation: Concepts, evidence, and implications. Academy of Management Review, 20(1): 65-91.

Edland, A., \& Svenson, O. 1993. Judgment and Decision Making Under Time Pressure. In O. Svenson \& A. J. Maule (Eds.), Time Pressure and Stress in Human Judgment and Decision Making: 27-40. Springer, Boston, MA.

Effron, D. A., \& Monin, B. 2010. Letting People Off the Hook: When Do Good Deeds Excuse Transgressions? Personality and Social Psychology Bulletin, 0146167210385922.

Elsbach, K. D., \& Sutton, R. I. 1992. Acquiring Organizational Legitimacy Through Illegitimate Actions: A Marriage of Institutional and Impression Management Theories. Academy of Management Journal, 35(4): 699-738.

Emerson, R. M. 1962. Power-Dependence Relations. American Sociological Review, 27(1): 3141. 
Fiske, S. T., \& Neuberg, S. L. 1990. A Continuum of Impression Formation, from CategoryBased to Individuating Processes: Influences of Information and Motivation on Attention and Interpretation. In M. P. Zanna (Ed.), Advances in Experimental Social Psychology, vol. 23: 1-74. Academic Press.

Flynn, F. J. 2003. How Much Should I Give and How Often? The Effects of Generosity and Frequency of Favor Exchange on Social Status and Productivity. Academy of Management Journal, 46(5): 539-553.

Flynn, F. J., Reagans, R. E., Amanatullah, E. T., \& Ames, D. R. 2006. Helping one's way to the top: Self-monitors achieve status by helping others and knowing who helps whom. Journal of Personality and Social Psychology, 91(6): 1123-1137.

Fombrun, C., \& Shanley, M. 1990. What's in a Name? Reputation Building and Corporate Strategy. Academy of Management Journal, 33(2): 233-258.

Foti, R. J., \& Hauenstein, N. M. A. 2007. Pattern and variable approaches in leadership emergence and effectiveness. The Journal of Applied Psychology, 92(2): 347-355.

Fragale, A. R., Rosen, B., Xu, C., \& Merideth, I. 2009. The higher they are, the harder they fall: The effects of wrongdoer status on observer punishment recommendations and intentionality attributions. Organizational Behavior and Human Decision Processes, 108(1): 53-65.

Giordano, P. C. 1983. Sanctioning the High-Status Deviant: An Attributional Analysis. Social Psychology Quarterly, 46(4): 329-342.

Graffin, S. D., Bundy, J., Porac, J. F., Wade, J. B., \& Quinn, D. P. 2013. Falls from Grace and the Hazards of High Status The 2009 British MP Expense Scandal and Its Impact on Parliamentary Elites. Administrative Science Quarterly, 58(3): 313-345.

Hakim, D., \& Santos, F. 2008, March 24. GOP Consultant says he reported Spitzer trysts in 2007. New York Times. http://www.nytimes.com/2008/03/24/nyregion/24spitzer.html.

Halevy, N., Chou, E. Y., Cohen, T. R., \& Livingston, R. W. 2012. Status conferral in intergroup social dilemmas: Behavioral antecedents and consequences of prestige and dominance. Journal of Personality and Social Psychology, 102(2): 351-366.

Harder, J. W. 1992. Play for Pay: Effects of Inequity in a Pay-for-Performance Context. Administrative Science Quarterly, 37(2): 321-335.

Harris, J., \& Bromiley, P. 2007. Incentives to Cheat: The Influence of Executive Compensation and Firm Performance on Financial Misrepresentation. Organization Science, 18(3): $350-367$.

Haselhuhn, M. P., Ormiston, M. E., \& Wong, E. M. 2015. Men's Facial Width-to-Height Ratio Predicts Aggression: A Meta-Analysis. PLOS ONE, 10(4): e0122637.

Hays, N. A., \& Bendersky, C. 2015. Not all inequality is created equal: Effects of status versus power hierarchies on competition for upward mobility. Journal of Personality and Social Psychology, 108(6): 867-882.

Helou, A., \& Park, G. 2001. Is There a Signaling Effect of Underwriter Reputation? Journal of Financial Research, 24(1): 27-43.

Henrich, J., \& Gil-White, F. J. 2001. The evolution of prestige: freely conferred deference as a mechanism for enhancing the benefits of cultural transmission. Evolution and Human Behavior, 22(3): 165-196.

Hiebert-White, J. 2008, December 12. Daschle Nominated To Head HHS, Health Reform Office | Health Affairs. Health Affairs. https://www.healthaffairs.org/do/10.1377/hblog20081212.000474/full/. 
Hollander, E. P. 1958. Conformity, status, and idiosyncrasy credit. Psychological Review, 65(2): 117.

Howell, T. M., Harrison, D. A., Burris, E. R., \& Detert, J. R. 2015. Who gets credit for input? Demographic and structural status cues in voice recognition. Journal of Applied Psychology, 100(6): 1765-1784.

Idson, T., \& Kahane, L. 2000. Team effects on compensation: an application to salary determination in the National Hockey League. Economic Inquiry, 38(2): 345-357.

Jensen, M., \& Roy, A. 2008. Staging Exchange Partner Choices: When Do Status and Reputation Matter? Academy of Management Journal, 51(3): 495-516.

Johnston, M. 2018. Was Bruins star Brad Marchand's clipping penalty a reputation call? Sportsnet. https://www.sportsnet.ca/hockey/nhl/bruins-star-brad-marchands-clippingpenalty-reputation-call/.

Jones, M. V., Paull, G. C., \& Erskine, J. 2002. The impact of a team's aggressive reputation on the decisions of association football referees. Journal of Sports Sciences, 20(12): 9911000 .

Jussim, L., Coleman, L. M., \& Lerch, L. 1987. The nature of stereotypes: A comparison and integration of three theories. Journal of Personality and Social Psychology, 52(3): 536546.

Kakkar, H., \& Sivanathan, N. 2017. When the appeal of a dominant leader is greater than a prestige leader. Proceedings of the National Academy of Sciences, 114(26): 6734-6739.

Karelaia, N., \& Keck, S. 2013. When deviant leaders are punished more than non-leaders: The role of deviance severity. Journal of Experimental Social Psychology, 49(5): 783-796.

Kim, J. W., \& King, B. G. 2014. Seeing Stars: Matthew Effects and Status Bias in Major League Baseball Umpiring. Management Science, 60(11): 2619-2644.

Kim, P. H., Dirks, K. T., Cooper, C. D., \& Ferrin, D. L. 2006. When more blame is better than less: The implications of internal vs. external attributions for the repair of trust after a competence- vs. integrity-based trust violation. Organizational Behavior and Human Decision Processes, 99(1): 49-65.

Kim, P. H., Ferrin, D. L., Cooper, C. D., \& Dirks, K. T. 2004. Removing the shadow of suspicion: the effects of apology versus denial for repairing competence- versus integritybased trust violations. Journal of Applied Psychology, 89(1): 104-118.

Kochan, T. A., \& Rubinstein, S. A. 2000. Toward a stakeholder theory of the firm: The Saturn partnership. Organization Science, 11(4): 367-386.

Laustsen, L., \& Petersen, M. B. 2015. Does a competent leader make a good friend? Conflict, ideology and the psychologies of friendship and followership. Evolution and Human Behavior, 36(4): 286-293.

Likens, J. 2011. Shots, Fenwick and Corsi. http://objectivenhl.blogspot.com/2011/02/shotsfenwick-and-corsi.html.

Loeffler, R. L., \& Lawson, T. J. 2002. Age and occupational status of defendant in relation to mock juror sentencing recommendations. Current Psychology, 21(3): 289.

Lord, R. G., de Vader, C. L., \& Alliger, G. M. 1986. A meta-analysis of the relation between personality traits and leadership perceptions: An application of validity generalization procedures. Journal of Applied Psychology, 71(3): 402-410.

Macdonald, B. 2012. Adjusted plus-minus for NHL players using ridge regression. $\boldsymbol{U R \boldsymbol { L }}$ Http://Arxiv. Org/Abs/1201.0317 V1. 
Magee, J. C., \& Galinsky, A. D. 2008. Social Hierarchy: The Self-Reinforcing Nature of Power and Status. The Academy of Management Annals, 2(1): 351-398.

Malle, B. F., \& Knobe, J. 1997. The Folk Concept of Intentionality. Journal of Experimental Social Psychology, 33(2): 101-121.

Maner, J. K., \& Case, C. R. 2016. Dominance and Prestige: Dual Strategies for Navigating Social Hierarchies. In J. M. Olson \& M. P. Zanna (Eds.), Advances in Experimental Social Psychology, vol. 54: 129-180. Academic Press.

Maner, J. K., \& Mead, N. L. 2010. The essential tension between leadership and power: When leaders sacrifice group goals for the sake of self-interest. Journal of Personality and Social Psychology, 99(3): 482-497.

Marques, J. M., \& Paez, D. 1994. The 'Black Sheep Effect': Social Categorization, Rejection of Ingroup Deviates, and Perception of Group Variability. European Review of Social Psychology, 5(1): 37-68.

Marr, J. C., \& Thau, S. 2014. Falling from great (and not-so-great) heights: How initial status position influences performance after status loss. Academy of Management Journal, 57(1): 223-248.

Mazar, N., Amir, O., \& Ariely, D. 2008. The Dishonesty of Honest People: A Theory of SelfConcept Maintenance. Journal of Marketing Research, 45(6): 633-644.

Mazur, A., \& Booth, A. 1998. Testosterone and dominance in men. Behavioral and Brain Sciences, 21(03): 353-363.

McDonnell, M.-H., \& King, B. G. 2018. Order in the Court: How Firm Status and Reputation Shape the Outcomes of Employment Discrimination Suits. American Sociological Review, 83(1): 61-87.

Merton, R. K. 1968. The Matthew Effect in Science. Science, 159(3810): 56-63.

Mileva, V. R., Cowan, M. L., Cobey, K. D., Knowles, K. K., \& Little, A. C. 2014. In the face of dominance: Self-perceived and other-perceived dominance are positively associated with facial-width-to-height ratio in men. Personality and Individual Differences, 69: 115118.

Miller, D. T. 1999. The norm of self-interest. The American Psychologist, 54(12): 1053-1060.

Miller, D. T., \& Effron, D. A. 2010. Psychological license: When it is needed and how it functions. In M. P. Zanna \& J. M. Olson (Eds.), Advances in Experimental Social Psychology, vol. 43: 115-155. Academic Press.

Mishina, Y., Dykes, B. J., Block, E. S., \& Pollock, T. G. 2010. Why “Good” Firms do Bad Things: The Effects of High Aspirations, High Expectations, and Prominence on the Incidence of Corporate Illegality. Academy of Management Journal, 53(4): 701-722.

Monin, B., \& Miller, D. T. 2001. Moral credentials and the expression of prejudice. Journal of Personality and Social Psychology, 81(1): 33-43.

Nelissen, R. M. A., \& Zeelenberg, M. 2009. Moral emotions as determinants of third-party punishment: Anger, guilt, and the functions of altruistic sanctions. Judgment and Decision Making, 4(7): 543-553.

Nemiroff, P. M., \& Pasmore, W. A. 2001. Lost at sea: A consensus-seeking task. The Pfeiffer Book of Successful Team-Building Tools: Best of the Annuals, 165-172.

NHL. 2014. NHL announces rules changes for 2014-15 season. NHL.com. https://www.nhl.com/news/nhl-announces-rules-changes-for-2014-15-season/c-730165.

Pearson, C. M., \& Clair, J. A. 1998. Reframing Crisis Management. Academy of Management Review, 23(1): 59-76. 
Pettit, N. C., Sivanathan, N., Gladstone, E., \& Marr, J. C. 2013. Rising Stars and Sinking Ships Consequences of Status Momentum. Psychological Science, 24(8): 1579-1584.

Podolny, J. M. 1993. A status-based model of market competition. American Journal of Sociology, 829-872.

Polman, E., Pettit, N. C., \& Wiesenfeld, B. M. 2013. Effects of wrongdoer status on moral licensing. Journal of Experimental Social Psychology, 49(4): 614-623.

Rhee, M., \& Haunschild, P. R. 2006. The Liability of Good Reputation: A Study of Product Recalls in the U.S. Automobile Industry. Organization Science, 17(1): 101-117.

Roberts, P. W., \& Dowling, G. R. 2002. Corporate reputation and sustained superior financial performance. Strategic Management Journal, 23(12): 1077-1093.

Rosoff, S. M. 1989. Physicians as criminal defendants: Specialty, sanctions, and status liability. Law and Human Behavior, 13(2): 231-236.

Rudman, L. A., \& Fairchild, K. 2004. Reactions to Counterstereotypic Behavior: The Role of Backlash in Cultural Stereotype Maintenance. Journal of Personality and Social Psychology, 87(2): 157-176.

Ryan, D. 2017, September 22. For the love of God, NHL: Enough with all the dumb penalty calls. Stanley Cup of Chowder. https://www.stanleycupofchowder.com/2017/9/22/16348538/nhl-faceoff-penaltiesslashing-penalties-bruins-flyers-too-many-penalties-please-make-it-stop.

Sahadi, J. 2008, November 24. Obama names his economic dream team. CNN Money. https://money.cnn.com/2008/11/24/news/economy/obama_economic_team/.

Salmon, F. 2018, April 19. Why the Starbucks Racial Bias Training Is More Than Just Good PR. Slate Magazine. https://slate.com/business/2018/04/why-the-starbucks-racial-biastraining-is-more-than-just-good-pr.html.

Saporito, B. 1998. Taking a look inside Nike's factories. Time. http://content.time.com/time/magazine/article/0,9171,138854,00.html.

Scully, G. W. 1974. Pay and Performance in Major League Baseball. The American Economic Review, 64(6): 915-930.

Shultz, T. R., \& Wright, K. 1985. Concepts of negligence and intention in the assignment of moral responsibility. Canadian Journal of Behavioural Science/Revue Canadienne Des Sciences Du Comportement, 17(2): 97-108.

Skarlicki, D. P., \& Kulik, C. T. 2004. Third-party reactions to employee (mis)treatment : A justice perspective. Research in Organizational Behavior, 26: 183-229.

Sommers, S. R., \& Ellsworth, P. C. 2000. Race in the Courtroom: Perceptions of Guilt and Dispositional Attributions. Personality and Social Psychology Bulletin, 26(11): 13671379.

Spak, K. 2009, January 21. Geithner Sorry, Blames TurboTax. Newser. http://www.newser.com/story/48573/geithner-sorry-blames-turbotax.html.

Staff, T. N. R. 2012, April 17. A Brief Audit of Politicians' Tax Problems. The New Republic. https://newrepublic.com/article/102725/politicians-tax-day-tax-evasion-audit.

Surowiecki, J. 2016, April 26. No Refereeing Is Bad Refereeing. The New Yorker. https://www.newyorker.com/news/sporting-scene/the-n-h-l-playoffs-no-refereeing-isbad-refereeing.

Swigert, V. L., \& Farrell, R. A. 1977. Normal Homicides and the Law. American Sociological Review, 42(1): 16-32. 
Tabuchi, H. 2013, July 3. Suspended Sentences in Olympus Fraud Case. The New York Times. http://www.nytimes.com/2013/07/04/business/global/suspended-sentences-in-olympusaccounting-fraud-case.html.

Van der Vegt, G. S., Bunderson, J. S., \& Oosterhof, A. 2006. Expertness Diversity and Interpersonal Helping in Teams: Why those who Need the Most Help End Up Getting the Least. Academy of Management Journal, 49(5): 877-893.

Van Kleef, G. A., Homan, A. C., Finkenauer, C., Blaker, N. M., \& Heerdink, M. W. 2012. Prosocial norm violations fuel power affordance. Journal of Experimental Social Psychology, 48(4): 937-942.

van Prooijen, J. W. 2006. Retributive Reactions to Suspected Offenders: The Importance of Social Categorizations and Guilt Probability. Personality and Social Psychology Bulletin, 32(6): 715-726.

Van Vugt, M. 2006. Evolutionary Origins of Leadership and Followership. Personality and Social Psychology Review, 10(4): 354-371.

Verdonck, A., Gaethofs, M., Carels, C., \& Zegher, F. de. 1999. Effect of low-dose testosterone treatment on craniofacial growth in boys with delayed puberty. The European Journal of Orthodontics, 21(2): 137-143.

Vincent, C., \& Eastman, B. 2009. Determinants of Pay in the NHL: A Quantile Regression Approach. Journal of Sports Economics, 10(3): 256-277.

von Rueden, C., Gurven, M., \& Kaplan, H. 2010. Why do men seek status? Fitness payoffs to dominance and prestige. Proceedings of the Royal Society of London B: Biological Sciences, 278(1715): 2223-2232.

Wade, J. B., Porac, J. F., Pollock, T. G., \& Graffin, S. D. 2006. The Burden of Celebrity: the Impact of Ceo Certification Contests on Ceo Pay and Performance. Academy of Management Journal, 49(4): 643-660.

Washington, M., \& Zajac, E. J. 2005. Status Evolution and Competition: Theory and Evidence. Academy of Management Journal, 48(2): 282-296.

Weidlich, T., \& Glovin, D. 2008, April 15. Bayou Hedge Fund Founder Sentenced to 20 Years for Fraud. The Washington Post. http://www.washingtonpost.com/wpdyn/content/article/2008/04/14/AR2008041402787.html.

Willer, R. 2009. Groups Reward Individual Sacrifice: The Status Solution to the Collective Action Problem. American Sociological Review, 74(1): 23-43.

Zeleny, J., \& Stout, D. 2009, February 3. Daschle Withdraws as Cabinet Nominee. The New York Times. https:/www.nytimes.com/2009/02/04/us/politics/04obama.html. 
Table 1 Means, Standard Deviations, and Inter-correlations for Study 1

\begin{tabular}{|c|c|c|c|c|c|c|c|c|c|c|c|c|c|c|c|c|c|}
\hline & VARIABLES & $M$ & $S D$ & 1 & 2 & 3 & 4 & 5 & 6 & 7 & 8 & 9 & 10 & 11 & 12 & 13 & 14 \\
\hline 1 & Height (inches) & 73.18 & 2.09 & 1 & & & & & & & & & & & & & \\
\hline 2 & Weight (kg) & 92.19 & 6.63 & $0.73^{* * *}$ & 1 & & & & & & & & & & & & \\
\hline 3 & BMI & 26.67 & 1.32 & $-0.1^{* * *}$ & $0.61^{* * *}$ & 1 & & & & & & & & & & & \\
\hline 4 & Age & 27.73 & 4.27 & -0.05 & $0.1^{* * *}$ & $0.21^{* * *}$ & 1 & & & & & & & & & & \\
\hline 5 & Shooting Hand a & 1.38 & 0.48 & -0.03 & -0.03 & 0.00 & -0.05 & 1 & & & & & & & & & \\
\hline 6 & Playing position ${ }^{\mathrm{b}}$ & 2.25 & 1.05 & -0.04 & $0.05^{*}$ & $0.13^{* * *}$ & $0.08^{* * *}$ & $0.15^{* * *}$ & 1 & & & & & & & & \\
\hline 7 & Draft Year ${ }^{\mathrm{c}}$ & 12.82 & 5.05 & $-0.09^{* * *}$ & $-0.17^{* * *}$ & $-0.14^{* * *}$ & $-0.68^{* * *}$ & $0.06^{*}$ & -0.02 & 1 & & & & & & & \\
\hline 8 & Previous season punishment & 0.57 & 0.49 & $0.19^{* * *}$ & $0.3^{* * *}$ & $0.21^{* * *}$ & $0.11^{* * *}$ & 0.03 & $0.14^{* * *}$ & $-0.08^{* * *}$ & 1 & & & & & & \\
\hline 9 & Current Performance & -0.65 & 7.53 & 0.04 & 0.02 & -0.02 & 0.03 & 0.03 & -0.01 & $-0.11^{* * *}$ & 0.01 & 1 & & & & & \\
\hline 10 & Season ${ }^{\mathrm{d}}$ & 1.5 & 0.5 & 0.01 & 0.00 & -0.01 & -0.01 & 0.01 & 0.00 & $0.08^{* * *}$ & -0.05 & -0.05 & 1 & & & & \\
\hline 11 & Status & 2.66 & 2.11 & 0.04 & $0.07^{* *}$ & $0.06^{*}$ & $0.29^{* * *}$ & 0.01 & -0.03 & $-0.36^{* * *}$ & -0.04 & $0.24^{* * *}$ & 0.04 & 1 & & & \\
\hline 12 & Generalized Dominance (fWHR) & 2.01 & 0.14 & $0.06^{*}$ & 0.04 & -0.01 & $-0.09^{* * *}$ & -0.04 & -0.01 & 0.05 & $0.06^{*}$ & 0.03 & 0.02 & $0.16^{* * *}$ & 1 & & \\
\hline 13 & Prestige & 0 & 1.24 & 0.02 & 0.04 & 0.03 & 0.00 & 0.00 & $-0.05^{*}$ & $-0.07^{*}$ & $-0.07^{* *}$ & $0.14^{* * *}$ & $0.24^{* * *}$ & $0.59^{* * *}$ & $0.08^{* * *}$ & 1 & \\
\hline 14 & Punishment & 0.56 & 0.48 & $0.18^{* * *}$ & $0.27^{* * *}$ & $0.19^{* * *}$ & $0.06^{*}$ & $0.07^{* *}$ & $0.12^{* * *}$ & -0.04 & $0.62^{* * *}$ & $-0.07^{*}$ & 0.01 & $-0.06^{*}$ & $0.08^{* * *}$ & $-0.08^{* *}$ & 1 \\
\hline
\end{tabular}


Table 2 Results of Random Coefficient Modeling in Study 1

\begin{tabular}{|c|c|c|c|c|c|c|c|c|c|}
\hline \multirow[b]{2}{*}{ Variables } & \multirow[b]{2}{*}{ Model 1} & \multirow[b]{2}{*}{ Model 2} & \multirow[b]{2}{*}{ Model 3} & \multicolumn{3}{|c|}{ PUNISHMENT } & \multirow[b]{2}{*}{ Model 7} & \multirow[b]{2}{*}{ Model 8} & \multirow[b]{2}{*}{ Model 9} \\
\hline & & & & Model 4 & Model 5 & Model 6 & & & \\
\hline Prestige & & $\begin{array}{l}-.031^{* *} \\
(.012)\end{array}$ & $\begin{array}{l}-.019 \\
(.012)\end{array}$ & & $\begin{array}{l}-.018^{*} \\
(.009)\end{array}$ & & $\begin{array}{c}-.02^{*} \\
(.009)\end{array}$ & $\begin{array}{l}-.005 \\
(.01)\end{array}$ & $\begin{array}{c}-.012 \\
(.01)\end{array}$ \\
\hline Generalized Dominance X Status & & & & $\begin{array}{l}2.296^{*} \\
(.964)\end{array}$ & & $\begin{array}{c}3.452^{* * *} \\
(.74)\end{array}$ & $\begin{array}{c}3.522^{* * *} \\
(.739)\end{array}$ & & $\begin{array}{c}2.538^{* *} \\
(.887)\end{array}$ \\
\hline Prestige X Status & & & $\begin{array}{l}-.195^{* *} \\
(.064)\end{array}$ & & & & & $\begin{array}{c}-.214^{* * *} \\
(.05)\end{array}$ & $\begin{array}{c}-.119^{*} \\
(.06)\end{array}$ \\
\hline Status & $\begin{array}{l}.004 \\
(.057)\end{array}$ & $\begin{array}{l}.076 \\
(.075)\end{array}$ & $\begin{array}{l}.439^{* *} \\
(.141)\end{array}$ & $\begin{array}{l}-4.339^{*} \\
(1.844)\end{array}$ & $\begin{array}{c}.018 \\
(.058)\end{array}$ & $\begin{array}{c}-6.595^{* * *} \\
(1.415)\end{array}$ & $\begin{array}{c}-6.712^{* * *} \\
(1.414)\end{array}$ & $\begin{array}{c}.421^{* * *} \\
(.11)\end{array}$ & $\begin{array}{c}-4.609^{* *} \\
(1.761)\end{array}$ \\
\hline Generalized Dominance (fWHR) & $\begin{array}{l}.158^{*} \\
(.076)\end{array}$ & & & $\begin{array}{l}.153 \\
(.111)\end{array}$ & $\begin{array}{l}.173^{*} \\
(.076)\end{array}$ & $\begin{array}{l}-.036 \\
(.086)\end{array}$ & $\begin{array}{l}-.024 \\
(.086)\end{array}$ & $\begin{array}{l}.163^{*} \\
(.075)\end{array}$ & $\begin{array}{c}.026 \\
(.089)\end{array}$ \\
\hline Height & $\begin{array}{l}-4.614 \\
(3.695)\end{array}$ & & & & $\begin{array}{l}-4.455 \\
(3.690)\end{array}$ & $\begin{array}{l}-4.856 \\
(3.665)\end{array}$ & $\begin{array}{l}-4.696 \\
(3.658)\end{array}$ & $\begin{array}{l}-4.129 \\
(3.665)\end{array}$ & $\begin{array}{l}-4.446 \\
(3.655)\end{array}$ \\
\hline Weight & $\begin{array}{c}.054 \\
(.037)\end{array}$ & & & & $\begin{array}{c}.053 \\
(.037)\end{array}$ & $\begin{array}{c}.057 \\
(.037)\end{array}$ & $\begin{array}{c}.055 \\
(.037)\end{array}$ & $\begin{array}{l}.049 \\
(.034)\end{array}$ & $\begin{array}{c}.053 \\
(.037)\end{array}$ \\
\hline BMI & $\begin{array}{l}-.163 \\
(.129)\end{array}$ & & & & $\begin{array}{l}-.157 \\
(.129)\end{array}$ & $\begin{array}{l}-.173 \\
(.128)\end{array}$ & $\begin{array}{l}-.167 \\
(.127)\end{array}$ & $\begin{array}{l}-.145 \\
(.128)\end{array}$ & $\begin{array}{l}-.157 \\
(.127)\end{array}$ \\
\hline Age & $\begin{array}{l}.002 \\
(.007)\end{array}$ & & & & $\begin{array}{l}.002 \\
(.007)\end{array}$ & $\begin{array}{l}.001 \\
(.007)\end{array}$ & $\begin{array}{c}.001 \\
(.007)\end{array}$ & $\begin{array}{l}.001 \\
(.007)\end{array}$ & $\begin{array}{c}.001 \\
(.007)\end{array}$ \\
\hline Shooting Hand ${ }^{a}$ & $\begin{array}{c}.039 \\
(.023)\end{array}$ & & & & $\begin{array}{c}.039 \\
(.023)\end{array}$ & $\begin{array}{c}.039 \\
(.023)\end{array}$ & $\begin{array}{c}.04 \\
(.022)\end{array}$ & $\begin{array}{c}.041 \\
(.023)\end{array}$ & $\begin{array}{c}.041 \\
(.023)\end{array}$ \\
\hline \multicolumn{10}{|l|}{$\begin{array}{r}\text { Playing Position (Central as } \\
\text { baseline) }\end{array}$} \\
\hline Defender & $\begin{array}{l}-.007 \\
(.026)\end{array}$ & & & & $\begin{array}{l}-.008 \\
(.026)\end{array}$ & $\begin{array}{l}-.006 \\
(.026)\end{array}$ & $\begin{array}{l}-.007 \\
(.026)\end{array}$ & $\begin{array}{l}-.012 \\
(.026)\end{array}$ & $\begin{array}{c}-.01 \\
(.026)\end{array}$ \\
\hline Left Wing & $\begin{array}{l}-.005 \\
(.032)\end{array}$ & & & & $\begin{array}{l}-.008 \\
(.031)\end{array}$ & $\begin{array}{l}-.007 \\
(.031)\end{array}$ & $\begin{array}{l}-.009 \\
(.031)\end{array}$ & $\begin{array}{l}-.014 \\
(.031)\end{array}$ & $\begin{array}{l}-.012 \\
(.031)\end{array}$ \\
\hline Right Wing & $\begin{array}{l}.039 \\
(.032)\end{array}$ & & & & $\begin{array}{l}.035 \\
(.032)\end{array}$ & $\begin{array}{l}.038 \\
(.032)\end{array}$ & $\begin{array}{c}.034 \\
(.032)\end{array}$ & $\begin{array}{l}.036 \\
(.032)\end{array}$ & $\begin{array}{l}.035 \\
(.032)\end{array}$ \\
\hline
\end{tabular}




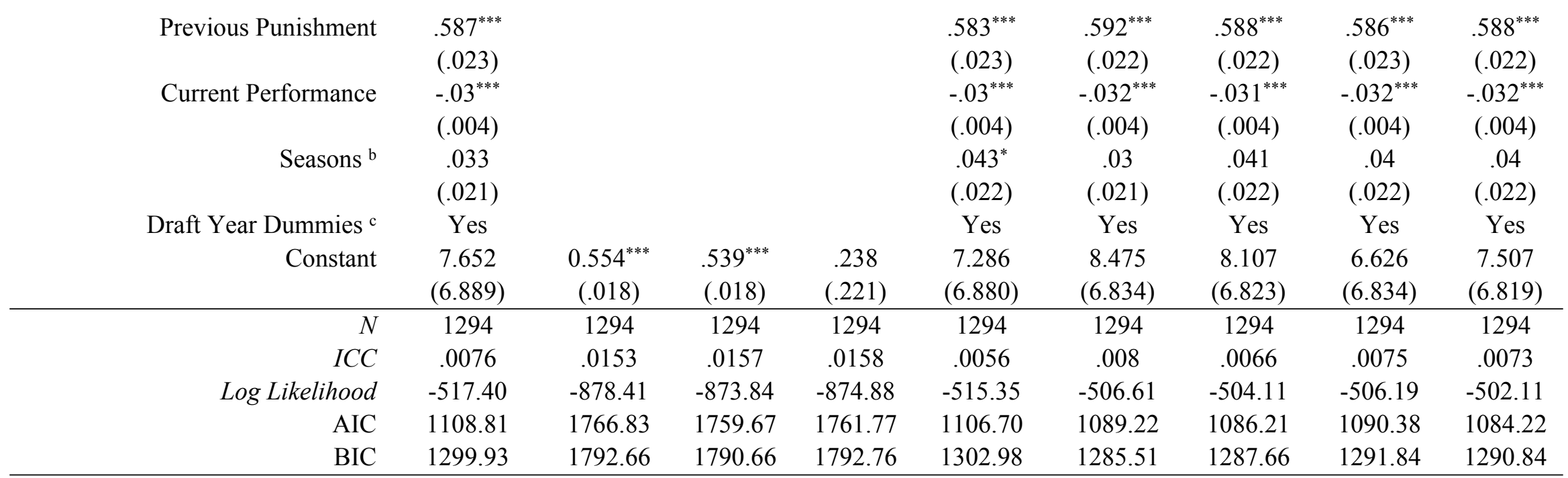

Notes: ${ }^{a}$ Categorical variable $1=$ Left Hand, $2=$ Right Hand; ${ }^{\mathrm{b}}$ Categorical variable $0=2013-14$ season, $1=2014-15$ season; ${ }^{\mathrm{c}}$ This comprises of 22 fixed effect for the year in which a player was first drafted in the NHL; Standard errors in parentheses; ${ }^{*} p<0.05,{ }^{* *} p<0.01,{ }^{* * *} p<0.001$

Table 3 ANOVA results analysis using number of hard questions assigned as the criterion variable in Study 2

\begin{tabular}{cccccccc}
\hline Predictor & $\begin{array}{c}\text { Sum of } \\
\text { Squares }\end{array}$ & $d f$ & Mean Square & $F$ & $p$ & & $\begin{array}{c}\eta^{2} \\
{[\mathrm{LL}, \mathrm{UL}]}\end{array}$ \\
\hline & & & & & & \\
Condition $^{\mathrm{a}}$ & 2.526 & 1 & 2.526 & 4.8 & .03 & .03 & {$[.0, .10]$} \\
Residuals & 78.95 & 150 & .526 & & & \\
\hline
\end{tabular}

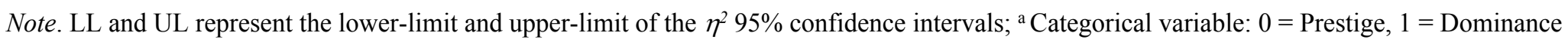


Table 4 Results of ANOVA analysis in Study 3

\begin{tabular}{lccccccc}
\hline & \multicolumn{3}{c}{ DV = PUNISHMENT } & & & & \\
Predictor & Sum of Squares & $d f$ & Mean Square & $F$ & $p$ & $\eta^{2}$ & $\eta^{2}$ 95\% CI [LL, UL] \\
\hline & & & & & & \\
Prestige $^{\mathrm{a}}$ & 109.74 & 1 & 109.74 & 37.8 & $<.001$ & .072 & {$[.034, .119]$} \\
Dominance $^{\mathrm{b}}$ & 42.58 & 1 & 42.58 & 14.67 & $<.001$ & .029 & {$[.007, .064]$} \\
Dominance X Prestige $^{\text {Residuals }}$ & 1.32 & 1 & 1.32 & .45 & .50 & .001 & {$[0, .014]$} \\
\hline
\end{tabular}

\begin{tabular}{|c|c|c|c|c|c|c|c|}
\hline \multirow[b]{2}{*}{ Predictor } & \multirow[b]{2}{*}{ Sum of Squares } & \multicolumn{3}{|c|}{ DV = INTENTIONALITY } & \multirow[b]{2}{*}{$p$} & \multirow[b]{2}{*}{$\eta^{2}$} & \multirow[b]{2}{*}{$\eta^{2} 95 \% \mathrm{CI}[\mathrm{LL}, \mathrm{UL}]$} \\
\hline & & $d f$ & Mean Square & $F$ & & & \\
\hline Prestige $^{\mathrm{a}}$ & 150.18 & 1 & 150.18 & 45.47 & $<.001$ & .085 & {$[.044, .135]$} \\
\hline Dominance ${ }^{b}$ & 52.71 & 1 & 52.71 & 15.96 & $<.001$ & .032 & {$[.008, .07]$} \\
\hline Dominance X Prestige & .003 & 1 & .003 & .0 & .98 & .000 & {$[0, .000]$} \\
\hline Residuals & 1608.34 & 487 & 3.30 & & & & \\
\hline \multirow[b]{2}{*}{ Predictor } & \multicolumn{6}{|c|}{ DV = MORAL CREDENTIALS } & \\
\hline & Sum of Squares & $d f$ & Mean Square & $F$ & $p$ & $\eta^{2}$ & $\eta^{2} 95 \% \mathrm{CI}[\mathrm{LL}, \mathrm{UL}]$ \\
\hline Prestige $^{\mathrm{a}}$ & 127.14 & 1 & 127.14 & 44.79 & $<.001$ & .084 & {$[.043, .134]$} \\
\hline Dominance ${ }^{b}$ & 13.08 & 1 & 13.08 & 4.61 & .03 & .01 & {$[.000, .033]$} \\
\hline Dominance X Prestige & 1.16 & 1 & 1.16 & .41 & .52 & .001 & {$[0, .014]$} \\
\hline Residuals & 1382.46 & 487 & 2.84 & & & & \\
\hline
\end{tabular}

Note. LL and UL represent the lower-limit and upper-limit of the $\eta^{2} 95 \%$ confidence intervals; ${ }^{a}$ Categorical variable: $0=$ Low, $1=$ High; ${ }^{b}$ Categorical variable: 0 = Low, 1 = High; 
Figure 1 Mediation Model in Study 3

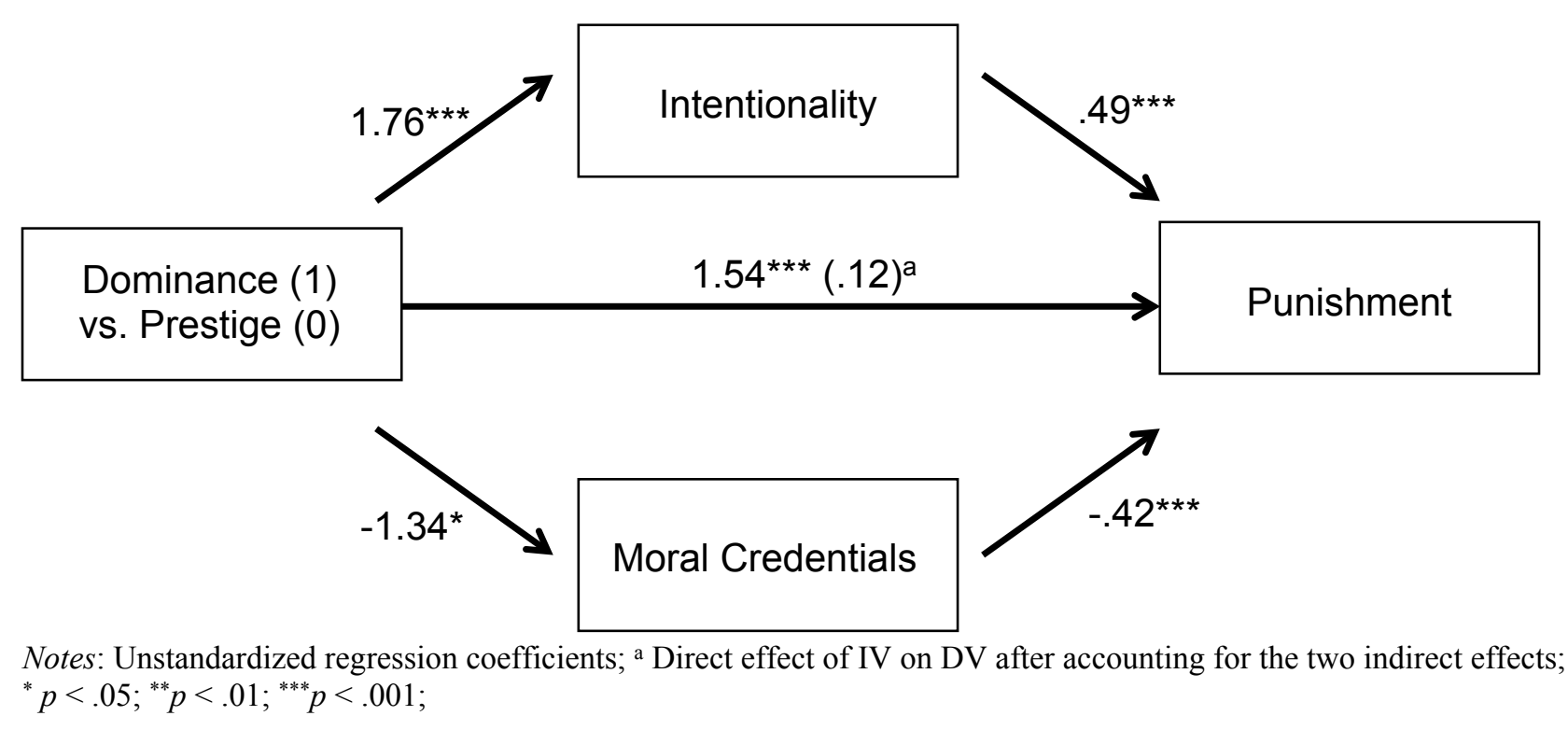


Hemant Kakkar (hkakkar@london.edu) is a doctoral candidate in the Organisational Behaviour Department of the London Business School. His research examines the influence of status within social hierarchies on individuals' psychology and their corresponding behaviors. Additionally, his research also explores both positive and negative forms of organizational deviance.

Niro Sivanathan (nsivanathan@london.edu) is an associate professor in the Organisational Behaviour Department of the London Business School. He received his $\mathrm{PhD}$ from the Kellogg School of Management. His research explores how social hierarchy, through the psychological experience of power and status, regulates our judgment and behaviors. In addition he studies how our motivation to maintain the integrity of the self, influences decision-making.

Matt Gobel (gobel@sagecenter.ucsb.edu) received his PhD in Experimental Psychology from the University College London. He is a recipient of multiple prestigious research fellowships including from the SAGE Center for the Study of the Mind and the Japan Society for the Promotion of Science. Matt Gobel's research focuses on the study of social hierarchies across different levels of analysis from broad cultural differences to low-level cognitive mechanisms using diverse methodologies including eye tracking technology and electroencephalography. 